\title{
5
}

\section{Molecular Markers, Genetic Maps and QTLs for Molecular Breeding in Peanut}

\author{
Manish K Pandey, ${ }^{1,2}$ Baozhu Guo, ${ }^{2} \mathrm{C}$ Corley Holbrook, ${ }^{3}$ P Janila, ${ }^{1}$ \\ Xinyou Zhang, ${ }^{4}$ David J Bertioli, ${ }^{5}$ Sachiko Isobe, ${ }^{6}$ \\ Xuanqiang Liang ${ }^{7}$ and Rajeev K Varshney ${ }^{1,7,8,9, *}$
}

\begin{abstract}
Integration of plant breeding, genetics and genomics promises to foster genetic enthancement leading to increased productivity, oil quality and. resistance/tolerance to biotic and abiotic stresses. Recent advances in peanut have resulted in the development of genomic resources such as SSR markers, and genetic maps for diploids and tetraploids. Even though the tetraploid species have both the genomes, the genetic diversity observed in cultivated peanut maps has been low. Therefore, only partial $(<100$ loci) to low-moderate $(<300$ loci) genetic maps could be constructed. Consensus genetic maps were, therefore, constructed with thousands of marker loci using mapping information of multiple mapping populations in order to integrate as many markers as possible
\end{abstract}

\footnotetext{
International Crops Research Institute for the Semi-Arid Tropics (ICRISAT), Hyderabad, India. 2USDA-ARS, Crop Protection and Management Research Unit, Tifton, USA.

${ }^{3}$ USDA-ARS, Crop Genetics and Breeding Research Unit, Tifton, USA.

${ }^{4}$ Henan Academy of Agricultural Sciences, Zhengzhou, China.

${ }^{5}$ Universidade de Brasilia, Brasília, Brazil.

${ }^{6} \mathrm{Kazusa}$ DNA Research Institute, Kisarazu, Japan.

${ }^{7}$ Crops Research Institute, Guandong Academy of Agricultural Sciences, Guangzhou, China. ${ }^{8}$ CGIAR Generation Challenge Programme, c/ o CIMMYT, Mexico DF, Mexico.

${ }^{9}$ The University of Western Australia, Crawley, Australia.

*Corresponding author: r.k.varshney@cgiar.org
}

List of abbreviations after the text. 
on a single genetic map. Development of SNP markers should lead to even more dense genetic maps and use of these markers in routine breeding and genetic applications. Efforts with the available limited genomic resources led to the identification of linked markers for drought tolerance, oil quality and disease resistance in peanut through trait mapping. These developments also led to deployment of linked markers to improve disease resistance and oil quality. Ongoing efforts should lead to the availability of the whole-genome sequence in the near future, providing huge genomic resources, which will hasten the much needed linking of phenotype with markers/genome sequences. However, this can only be achieved with precise and high-throughput phenotyping for complex traits. Recent advances in peanut genomics and molecular breeding efforts provide hope for efficient genetic enhancement of peanut for production as well as quality constraints.

Keywords: Groundnut, Genetic maps, QTLmapping, Molecular markers, Molecular breeding, Genomic resources, Genetic improvement

\subsection{Introduction}

Peanut or groundnut (Arachis hypogaea L.), with current annual production of 38.0 million tons from an area of $24.0 \mathrm{~m}$ ha (http://faostat.fao.org), is the fourth-largest oilseed crop in the world and is mostly grown in semiarid regions with relatively low inputs of chemical fertilizers. The crop is cultivated in more than 100 countries of Asia, Africa and the Americas with the largest (more than two-third) contributions coming from China and India. Peanut plays important roles in food and nutritional security along with improving the livelihood of resource-poor farmers. Peanut seeds contain edible oil $(40-60 \%)$, protein $(20-40 \%)$, carbohydrate (10-20\%) and several nutritional components such as vitamin $\mathrm{E}$, niacin, calcium, phosphorus, magnesium, zinc, iron, riboflavin, thiamine and potassium. Several uses of peanut make it an excellent cash crop for domestic as well as international trade. The major share goes towards extraction of vegetable oil for use in cooking apart from its use in the confectionary industry and fodder, a major source for protein feed for animals.

Since peanut is generally grown in marginal environments in Asia and Africa, the crop is challenged by several stress factors including biotic and abiotic stresses. The lack of genetic and genomic resources has significantly hampered peanut improvement programs. The major constraints for low genetic enhancement of cultivated peanut is attributed to: (i) very recent origin and highly conserved genome (Young et al. 1996), (ii) availability of only one related tetraploid wild species (A. monticola) (Krapovickas and Gregory 1994), (iii) the species in other sections are mostly diploid and hence 
limited sexual compatibility with cultivated peanut, (iv) lack of information on genetic architecture of economically important traits of peanut, and $(v)$ limited availability of molecular markers, genetic maps and Quantitative Trait Loci (QTLs). Genomics tools offer great promise to overcome the complex genetic makeup of peanut but lack of minimum genomic and genetic resources has hampered such efforts. Major biotic stresses include Early Leaf Spot (ELS), Late Leaf Spot (LLS), leaf rust, mottle virus, rosette virus, aphids, jassids and thrips/Tomato Spotted Wilt Virus (TSWV). Drought is the major abiotic stress as $70 \%$ of the crop is grown in the semiarid tropics, which are characterized by low and erratic rainfall. In spite of the genetical obstacles listed above, some efforts were made towards crop improvement through stress management using conventional approaches. Furthermore, restricted gene flow due to differences in ploidy level has severely hampered transfer of desired alleles from diploid wild relatives and hence, the much needed broadening of the genetic base of the species could not be achieved so far. Thus, the increasing population pressure seems not to be managed alone with conventional approaches and needs integration of genomics tools with the peanut improvement programs.

Due to the increased availability of genomic tools in recent years, Genomics-Assisted Breeding (GAB) offers hope for accelerated peanut improvement. Additionally, integration of genomics tools should aid in diversifying the existing narrow genetic base of the peanut gene pool with useful alleles and in understanding the complexity of the large tetraploid genome for genetic enhancement of cultivated peanut. Recent years have witnessed much progress in better understanding of crop genomics and its integration with conventional breeding, referred to as genomics-assisted breeding (GAB) to practice precision breeding for target traits (Varshney et al. 2005, 2010a). This advancement has not been achieved uniformly for all important crops and most importantly, could handle only simpler traits. Nevertheless, recent results showed significant advantages over conventional breeding in handling traits which are difficult to manage through conventional phenotypic selection and GAB has been successfully demonstrated in several temperate cereal crops (Varshney et al. 2006) and some legume crops (Varshney et al. 2010b, 2012a, 2013). In addition, introgression/pyramiding of multiple recessive alleles can be achieved very efficiently in less time and with more accuracy along with pyramiding of several monogenic traits or QTLs for a single trait (Ribaut and Hoisington 1998; Xu and Crouch 2008; Varshney et al. 2009a,b) such as in the case of marker-assisted improvement to develop a high oleic version of the nematode resistant cultivar, Tifguard, less than three years (Chu et al. 2011; Holbrook et al. 2011). However, to advance GAB in peanut, information on available genetic variation in germplasm, availability of appropriate molecular markers and genotyping platforms, suitable genetic maps, 
precise phenotyping platforms and QTLs with high phenotypic variance are required.

In spite of the potential of molecular markers in crop improvement, peanut experienced slow progress in the area of developing genomic resources such as molecular markers and genetic maps until 2005. Since then significant progress has been achieved as a result of concerted efforts of the international peanut community resulting in the development of several thousands of markers, several genetic maps, dense consensus genetic maps, QTL mapping and molecular breeding for resistance/tolerance to biotic stresses for peanut improvement (Guo et al. 2011; Holbrook et al. 2011; Pandey et al. 2012a). The progress made in genomic resources such as molecular markers, genetic maps, QTL identification and marker-assisted breeding in peanut has started to make progress with the help of genomic resources and should help to overcome genetic bottlenecks, and result in accelerated breeding progress.

\subsection{Marker Development}

Among all the genomic resources, molecular markers have proved to have the most direct applications towards characterizing and harnessing available genetic variation. These markers have been used in several genetic studies such as germplasm characterization, trait mapping and most importantly molecular marker-assisted breeding (Guo et al. 2011; Holbrook et al. 2011; Pandey et al. 2012a). Although several marker systems such as Restriction. Fragment Length Polymorphisms (RFLPs), Random Amplified Polymorphic DNAs (RAPDs), Amplified Fragment Length Polymorphisms (AFLPs) and Diversity Arrays Technology (DArT) markers became available and proved their utility from time to time (Varshney et al. 2006; Gupta et al. 2010), Simple Sequence Repeats (SSRs) or microsatellites and Single Nucleotide Polymorphism (SNP) markers are currently the most preferred marker systems for genetic studies and breeding applications. Although SSR markers are very much in use in current plant breeding applications, due to high-throughput genotyping amenability, SNPs seem to have more potential for future marker systems.

Early generation marker systems (RFLPs, RAPDs and AFLPs) were used primarily for studying genetic diversity of peanut (Hilu and Stalker 1995; Kochert et al. 1996; Subramaniyan et al. 2000; Dwivedi et al. 2001; He and Prakash 2001; Herselman 2003; Bravo et al. 2006). In some cases, these markers were also used for construction of genetic maps (Halward et al. 1993; Burow et al. 2001; Milla 2003; Herselman et al. 2004; Garcia et al. 2005; Leal-Bertioli et al. 2009) and identification of associated QTLs (Herselman et al. 2004). However, the insufficient number of these markers and other discouraging reasons associated with them motivated researchers 
towards development and use of better marker systems. As a result, several hundred SSR markers were generated (Pandey et al. 2012a). Low diversity detected with SSR markers in the cultivated gene pool, however, demanded development of large-scale SSR markers for effective use in routine genetic and breeding applications. Therefore, aggressive efforts made worldwide during the last few years resulted in the development of $>13,000$ SSR markers from SSR-enriched libraries, Bacterial Artificial Chromosome (BAC)-end sequences, Expressed Sequence Tag (EST) sequences and transcript sequences generated by using 454/FLX sequencing technology (Table 5-1). After screening 4,485 SSR markers on a set of parental genotypes of several mapping populations, a set of highly informative SSR markers (199 SSRs with >0.50 PIC) along with polymorphism features of 946 novel SSR markers have been identified and these SSRs have been used for several genetic and breeding studies in peanut (Pandey et al. 2012b). Similarly, Zhao et al. (2012) and Macedo et al. (2012) have reported 143 and 66 highly informative $(\geq 0.50 \mathrm{PIC})$ SSR markers of the 1,343 and 78 polymorphic markers detected after screening 9,274 and 146 markers, respectively.

In addition, a DArT platform (ca. 15,000 features) has been developed at-DArT Pty Ltd (Australia) in collaboration-with ICRISAT (India), CIRAD (France) and Catholic University of Brasília and EMBRAPA (Brazil). However, the use of DArT arrays showed a very low level of polymorphism in tetraploid ( $\mathrm{AABB}$ ) genotypes as compared to moderate level of diversity among diploid (AA and BB) genotypes (Kilian 2008; Varshney et al. 2013a). The results indicated potential use of DArT markers in monitoring genome introgression from wild relatives into peanut lines but limited use in genetics and breeding applications in cultivated peanut.

Recently, SNP markers have also been developed but mainly in diploid Arachis species. In the case of cultivated species, these SNPs have not been very polymorphic. For instance, The University of Georgia (USA) identified 8,486 SNPs after comparing the 454/FLX transcript sequences of 17 genotypes (over $350 \mathrm{Mb}$ transcriptome data) with reference transcriptome of "Tifrunner" with moderately stringent filtering. An Mlumina GoldenGate SNP array with 1,536-SNPs with high confidence was designed and used for genotyping on a diverse panel of Arachis genotypes. The newly designed array worked successfully ( $>95 \%$ ) but very low polymorphism was detected for cultivated tetraploid genotypes (http://nespal.org/oziasakinslab/ projects/plant-biotechnology-peanut-grasses/peanut-snp-discovery/). Another parallel effort resulted in identification of SNPs between diploid genotypes for Tentative Orthologous Genes (TOGs) at the University of California-Davis (Douglas Cook, pers. comm.) and development of 768-SNP Hlumina GoldenGate array. Despite these arrays being very informative for diploid species, the study showed that homoeology between AA- and $\mathrm{BB}-$ genomes posed a major constraint in proper use of these arrays for 
84 Genetics, Genomics and Breeding of Peanuts

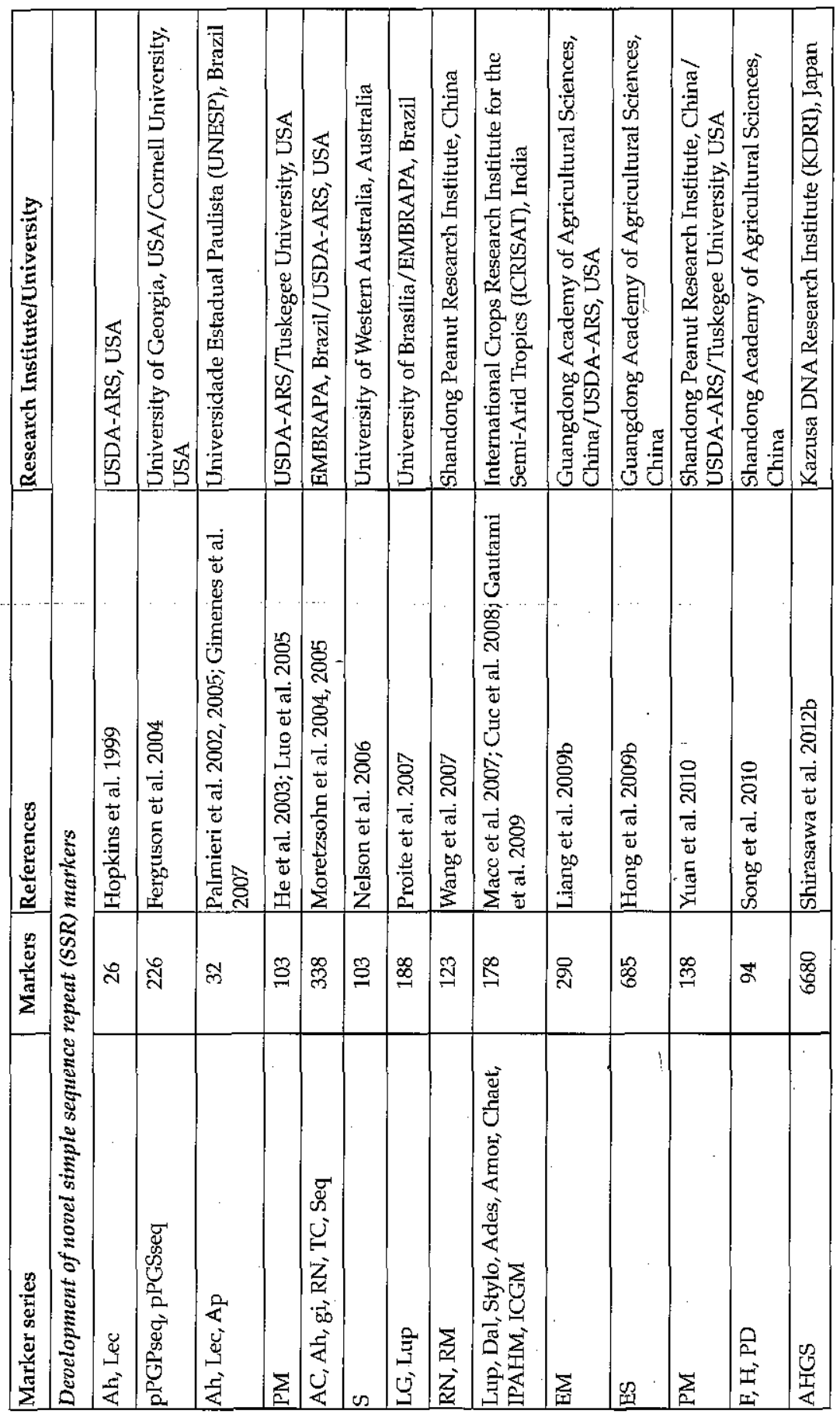




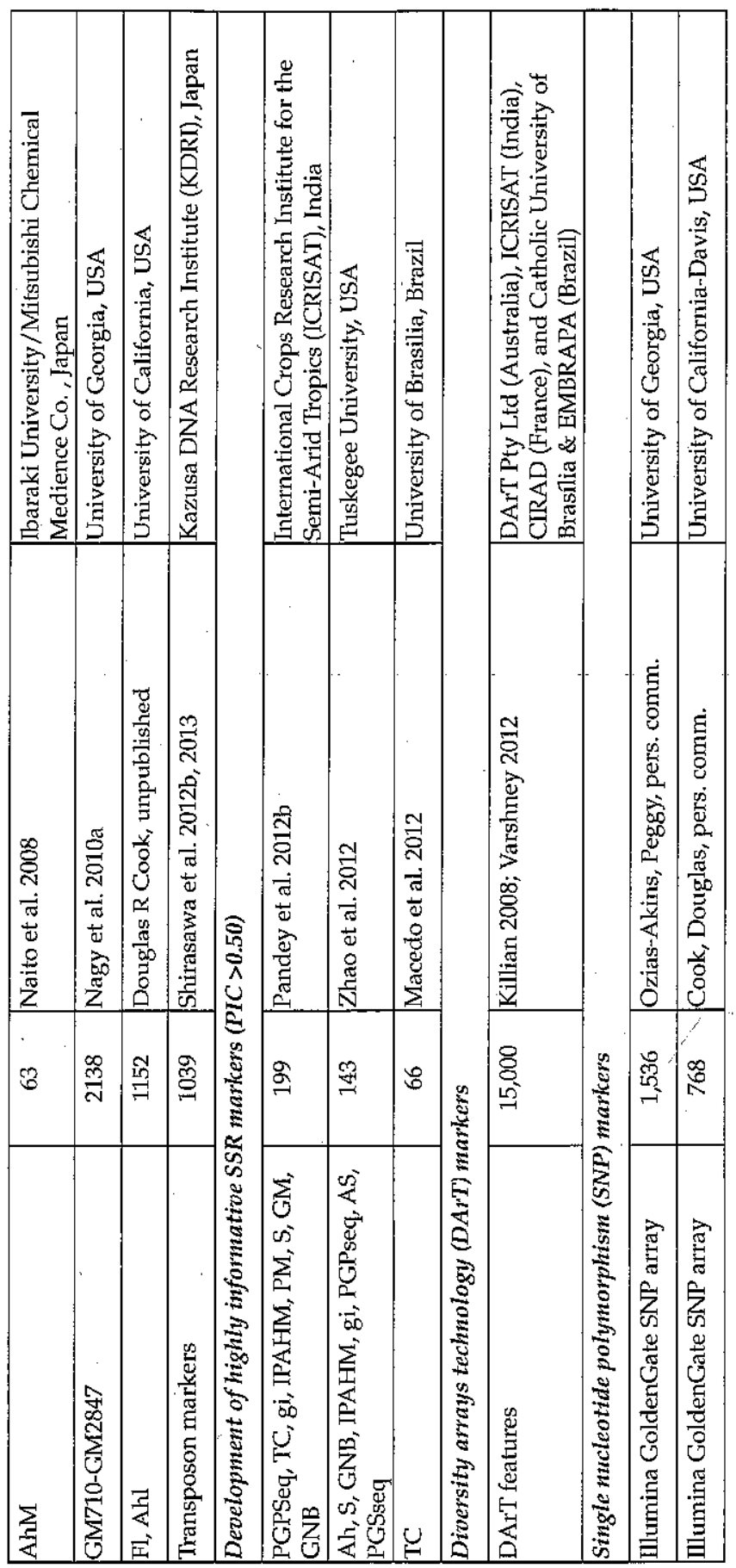


cultivated peanut. Hence, SSR markers remain the best choice for genetic and breeding studies in cultivated peanut until the whole genome sequence project is completed (www.PeanutBioscience.com). Also, in a collaborative effort with Peggy Ozias-Akins (University of Georgia, USA), ICRISAT has used a set of 96 highly informative SNPs in cultivated germplasm for conversion into KASPar assays. This assay was validated successfully for 91 SNPs (Khera et al. 2013).

Thus, thousands of molecular markers such as SSRs (13,596), DArTs $(15,000)$ and SNPs $(2304)$ are available (Table 5-1) for use in different genetical and breeding applications in peanut.

\subsection{Construction of Individual and Integrated Genetic Maps}

Although initial efforts for construction of genetic maps with 1st generation markers were reported in the last two decades of the 20th century, the majority of genetic maps were constructed between 2005-2012. Most of the initial genetic maps were developed based on mapping populations derived using diverse diploid parental genotypes in order to put the maximum number of markers on the maps. However, tetraploid populations have recently been used for construction of genetic maps as well as identification of QTLs for agronomically important traits.

\subsubsection{Genetic Maps for AA-Genome}

Genetic mapping in peanut was first started for AA-genome and marker systems such as RFLP (Halward et al. 1993), AFLP (Milla 2003), RAPD (Garcia et al. 2005), SSR (Moretzsohn et al. 2005; Leal-Bertioli et al. 2009) and SNP (Leal-Bertioli et al. 2009; Nagy et al. 2010a) were deployed for construction of several genetic maps (Table 5-2). The first genetic map of Arachis species was constructed with RFLP markers using $\mathrm{F}_{2}$ population (A. stenosperma $\times$ A. cardenasii) mapping a total of 117 RFLP loci (Halward et al. 1993). This map was followed by construction of three more genetic maps, all with different marker systems such as AFLP (A. kuhlmanni $\times$ A. diagoi, 102 AFLP loci; Milla 2003), RAPD (A. stenosperma $\times$ [A. stenosperma $\times$ A. cardenassi], 167 RAPDs; Garcia et al. 2005) and SSR markers (A. duranensis $\times$ A. stenosperma, 170 SSRs; Moretzsohn et al. 2005). Since, dense maps could not be constructed using one particular marker system, efforts were then made to use a range of marker systems for genetic mapping. These efforts resulted in the development of comparatively more saturated maps. For example, one of the above-described maps (Moretzsohn et al. 2005) with 170 SSR marker loci was then saturated with an additional 199 markers including AFLP, RFLP, SCAR and SNP markers and a consolidated map with 369 marker loci was prepared (Leal-Bertioli et al. 2009). Recently, the use of 


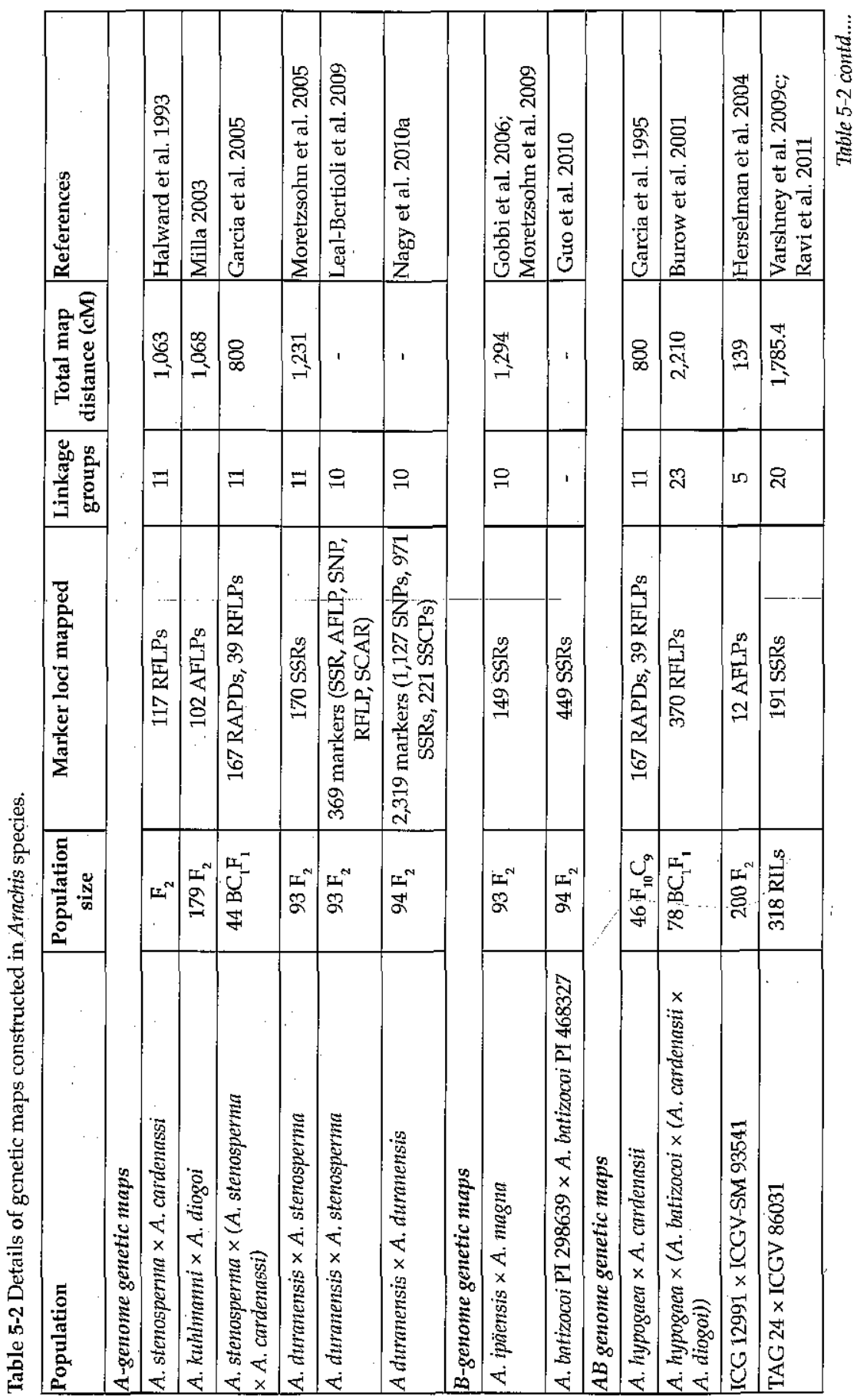




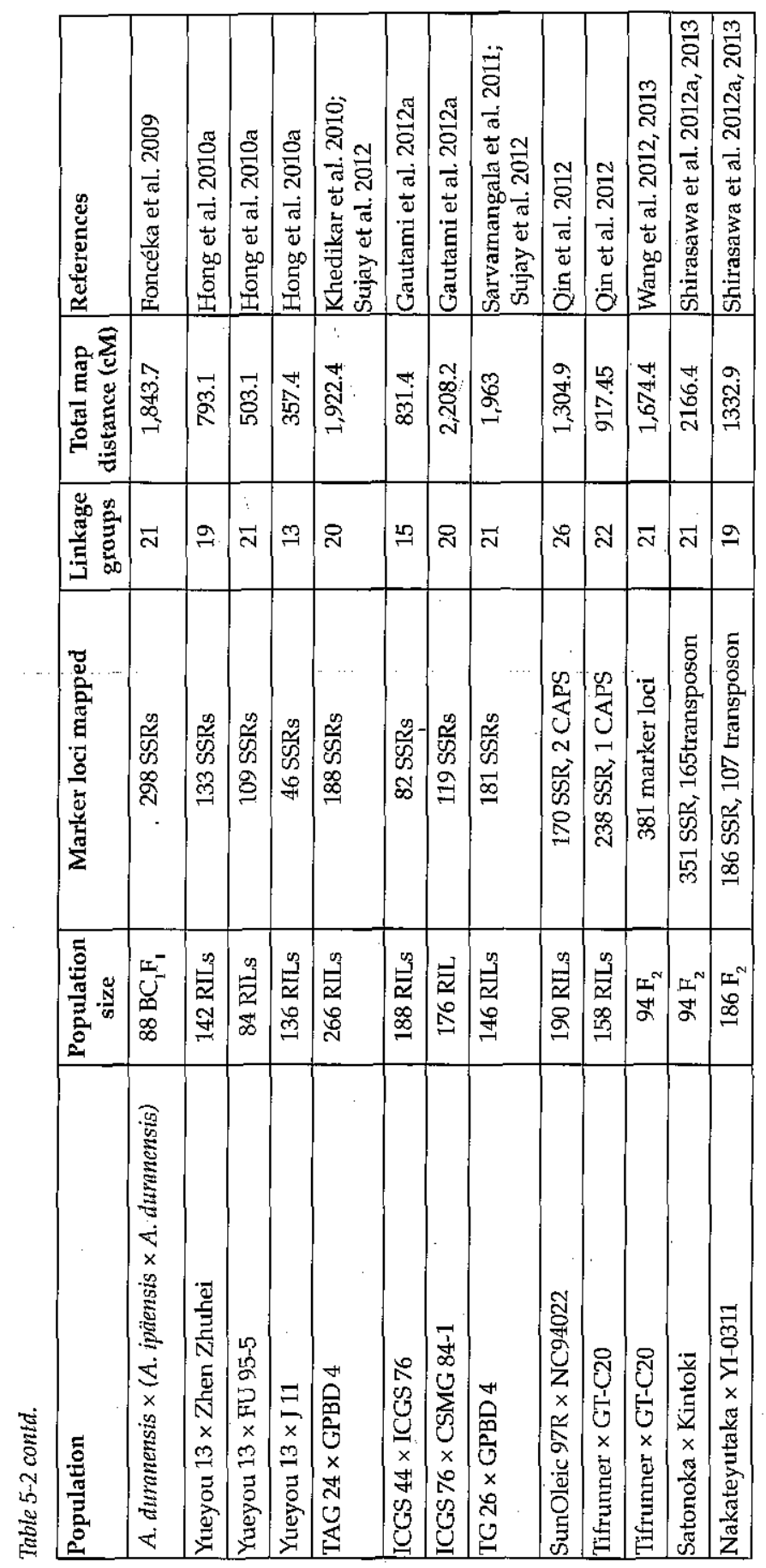


newly developed markers resulted in the development of an even denser genetic map using the $\mathrm{F}_{2}$ population derived from the cross (A. duranenis $\times$ A. duranensis) with 2,319 markers ( 971 SSRs, 221 single stranded DNA conformation polymorphism (SSCP) markers and 1,127 SNPs) mapped on 10 linkage groups (Nagy et al. 2010a). This map has the distinction of being the densest genetic map among all peanut diploid and tetraploid genetic maps. The latter two maps combined different marker systems such as AFLP, RFLP, SSR, SCAR, SSCPS and SNP markers.

\subsubsection{Genetic Maps for BB-Genome}

Only two maps have been reported for the BB-genome. One genetic map with 149 SSR loci on 11 linkage groups covering 1,294 cM genome, which was developed based on an $\mathrm{F}_{2}$ population ( 93 lines) derived from the cross between A. ipüensis (KG30076) and A. magna (KG30097) (Gobbi et al. 2006; Moretzsohn et al. 2009). The other genetic map was constructed with 449 SSR loci using again a $\mathrm{F}_{2}$ population derived from the cross $A$. batizocoi (PI298639) $\times$ A. batizocoi (PI468327) (Guo et al. 2010) (Table 5-2). Less polymorphism has been observed in BB-genome genetic maps compared to AA-genome genetic maps.

\subsubsection{Genetic Maps for Tetraploid (AABB) Genome}

Realizing the difficulty of transforming full information from diploids to cultivated peanuts, intensive efforts have recently been made for development of good genetic maps for tetraploid peanut. The very first effort to construct a genetic map for AABB genome was with RAPD and RFLP markers using the cross A. hypogaea and A. cardenassi. A total of 167 RAPD and 39 RFLP loci were mapped on 11 linkage groups covering 800 cM genome distance (Garcia et al. 1995) (Table 5-2). The second tetraploid genetic map was developed six years later with 370 RFLP loci mapped on 23 linkage groups (2,210 cM genome coverage) using a backcross population (78 $B C_{1} F_{1}$ lines) generated from the cross of $T x A G-6$ a synthetic amphidiploid line $\left.\left([\text { A. batizocoi } \times(A \text {. cardensii } \times \text { A. diogoi })]^{4 \times}\right)\right\}$ and Florunner (Burow et al. 2001). The next genetic map was constructed using AFLP markers, which resulted in development of a partial map with only 12 AFLP marker loci (Herselman et al. 2004). The comparison of diploid and tetraploid linkage maps revealed a high degree of colinearity between linkage groups (Burow et al. 2001; Jesubatham and Burow 2006) and identification of genome specific markers to assign A- and B-genome linkage groups in tetraploid genetic maps.

Low number of markers (RAPDs, RFLPs and AFLPs) and low genetic diversity among cultivated peanut seriously hampered the construction of 
dense genetic maps with 1st generation markers. Meanwhile, SSR markers have become more popular among geneticists and breeders due to their easy, reliable, cost-effective and robust genotyping nature. During the last decade we have witnessed the development of $>13,000$ SSR markers (Pandey et al. 2012a) and even identification of highly polymorphic genic and genomic SSR markers (Macedo et al. 2012; Pandey et al. 2012b; Zhao et al. 2012) that can be efficiently used in genetic diversity, mapping, QTL analysis and molecular breeding applications (Varshney et al. 2012). The first SSR-based genetic map using a Recombinant Inbred Line (RIL) population derived from TAG $24 \times$ ICGV 86031 was constructed with 135 SSR loci after screening a total of 1,145 SSR markers (Varshney et al. 2009c) (Table 5-2). This genetic map was further saturated to 191 SSR loci mapped on 20 linkage groups with 1,785 cM genome coverage (Ravi et al. 2011). Later genetic maps were all constructed using RIL populations (Hong et al. 2010a; Khedikar et al. 2010; Sarvamangala et al. 2011; Gautami et al. 2012a; Sujay et al. 2012; Qin et al. 2012) in addition to four maps, which are based on backcross (Fonceka et al. 2009) and $\mathrm{F}_{2}$ populations (Shirasawa et al. 2012a; Wang et al. 2012, 2013), respectively. As the mapping populations used for these maps also segregate for different traits, these maps have also been used for QTL analysis (see later).

The next genetic map based on SSRs was constructed with 298 marker loci on 21 linkage groups spanning a map distance of $1,843.7 \mathrm{cM}$ using a backcross mapping population with 88 individuals from the cross between a cultivar (Fleur 11) and a synthetic amphidiploid (A. duranensis $\times$ A. ipäensis) (Fonceka et al. 2009). This map showed overall colinearity between homologous linkage groups of both the A and B genomes, and also shed light on chromosomal rearrangements events prior to tetraploidization of cultivated species. This effort was also significant towards diversification of narrow cultivated gene pool. Hong et al. (2010a) reported the next three genetic maps based on three RILs namely Yueyou $13 \times$ Zhen Zhuhei, Yueyou $13 \times$ FU 95-5 and Yueyou $13 \times \mathrm{J} 11$ with $133(793.1 \mathrm{cM}), 109(503.1 \mathrm{cM})$ and $46(357.4 \mathrm{cM})$ marker loci, respectively. Using genotyping data from these three populations, a composite map containing 175 SSR markers in 22 linkage groups was developed (Table 5-2).

ICRISAT in collaboration with the University of Agricultural SciencesDharwad (UAS-D) initiated work on mapping QTLs for foliar diseases and in the process developed two new partial genetic maps using the RILs derived from the crosses TAG $24 \times$ GPBD 4 (Khedikar et al. 2010, $462.24 \mathrm{cM}$ genome coverage) and TG $26 \times$ GPBD 4 (Sarvamangala et al. $2011,657.9 \mathrm{cM}$ genome coverage) with 56 and 45 marker loci, respectively. Upon availability of more markers, these two maps were then saturated to $188(1,922.4 \mathrm{cM})$ and $181(1,963 \mathrm{cM})$ marker loci, respectively (Sujay et al. 2012). In addition to the above three updated maps (TAG $24 \times$ ICGV 
86031, TAG $24 \times$ GPBD 4 and TG $26 \times$ GPBD 4), two more genetic maps based on RIL populations namely ICGS $76 \times$ CSMG 84-1 and ICGS $44 \times$ ICGS 76 were developed with $119(2,208.2 \mathrm{cM}$ genome coverage) and 82 (831.4 cM genome coverage) marker loci, respectively. In parallel, Qin et al. (2012) reported construction of two genetic maps based on the two RIL populations namely Tifrunner $\times$ GT-C20 $(T$ population) and SunOleic $97 \mathrm{R} \times \mathrm{NC} 94022$ (S population). Individual genetic maps were constructed for $T$ and S populations with $236(1,213.4 \mathrm{cM})$ and $172(920.7 \mathrm{cM})$ marker loci, respectively (Qin et al. 2012). The effort towards saturation of $T$ and $S$ population genetic maps based on RILs is ongoing (Pandey et al. 2012c; Wang et al. 2013). The genetic map based on T population has the distinction of being the densest genetic map for cultivated peanut using an RIL mapping population. A segregating population ( $94 \mathrm{~F}_{2}$ individuals) of the $T$ population was used to develop a denser map with 333 marker loci on 28 linkage groups covering a genome distance of $1,674.4 \mathrm{cM}$ (Wang et al. 2012). Most recently, Shirasawa et al. (2012a) has reported construction of two genetic maps using the $\mathrm{F}_{2}$ population derived from the crosses, i.e., Satonoka $\times$ Kintoki (516 loci includes 351 SSRs and 165 transposon) and Nakateyutaka $\times$ - XI-0311 (293 loci includes 186 SSRs and 107 transposon) covering map distance of 2166.4 and $1332.9 \mathrm{cM}$, respectively. These two maps report mapping of transposon markers for the first time in peanut making this map (Satonoka $\times$ Kintoki) the most dense genetic map so far in tetraploid peanut.

As SNP markers have gained significant popularity during the past five years and have shown promising results in several crops, efforts are underway to integrate SNPs in the tetraploid maps of Arachis. For example, efforts at the University of California-Davis, USA (Richard Michelmore, pers. comm.) have recently started for generating ultra-high density genetic maps through low coverage, shotgun sequencing of diploid and tetraploid mapping populations and of reference sets of germplasm (Froenicke et al. 2011). These genetic materials represent populations from the AA genome (A. duranensis $\times A$. stenosperma), $\mathrm{BB}$ genome (A. ipäensis $\times A$. magna) and $A A B B$ genome $(A$. hypogaea cv. LAC Runner $\times$ synthetic amphidiploid of the two progenitor species) along with reference sets of ICRISAT (Upadhyaya et al. 2003), the US mini-core collection (Holbrook and Dong 2005) and the Chinese mini-core collection (Jiang et al. 2010). The idea behind this study is to identify SNPs in the diversity panel and to use these for estimating Linkage Disequilibrium (LD) and improving the genetic bins of highly dense genetic/consensus maps. Finally, these results will help in assisting and complementing the assembly of the reference genome sequence for peanut, which will be soon available for the peanut research community (www.PeanutBioscience.com). 


\subsubsection{Integrated or Consensus Genetic Maps}

Dense genetic linkage maps have several genetic and breeding applications such as trait mapping through linkage mapping or association analysis, marker-assisted breeding, map-based cloning and physical map alignment. Genome sequence information regarding marker order and location is very important for judicious application in breeding. Since it is almost impossible to map a large number of markers on a single map, the best option is to combine marker information of many individual genetic maps on to an integrated/consensus genetic map so that a maximum number of marker loci are mapped. Consensus maps have several advantages over individual genetic maps. The major advantages include ability: (1) to map several marker loci onto a single map, (2) to determine the relative position and stability of markers across populations and genome, (3) to provide evidence for chromosomal rearrangements and gene duplication, (4) to assign linkage groups to chromosome, and also (5) to provide the basic information for comparative genomic studies among related species and subspecies (Beavis and Grant 1991; Kianian and Quiros 1992; Hauge et al. 1993; Gentzbittel et al. 1995). Because of the above mentioned features, consensus genetic maps have been developed in many crop species like maize (Sharopova et al. 2002; Falque et al. 2005), wheat (Somers et al. 2004), barley (Varshney et al. 2007; Marcel et al. 2007), soybean (Song et al. 2004; Choi et al. 2007), pigeonpea.(Bohra et al. 2012) and more recently for peanut (Gautami et al. 2012b; Shirasawa et al. 2013) (Table 5-3).

The initial integrated genetic maps were developed based on two or three mapping populations. The first integrated genetic map was based on three RIL populations $\left(\mathrm{F}_{4: 6}\right)$ with 175 marker loci on 22 linkage groups with genome coverage of $885.4 \mathrm{cM}$ (Hong et al. 2010a). The next integrated map was developed using two mapping populations with 225 SSR loci covering a total map distance of 1,152.9 cM (Sujay et al. 2012). Another integrated map was based on three populations with 293 marker loci onto 20 linkage groups covering genome distance of $2,840.8 \mathrm{cM}$ (Gautami et al. 2012a). The latter two integrated maps were also used to show QTLs on the map, which were identified in individual populations for foliar disease resistance and drought related traits, respectively. The most recent integrated map was based on two mapping populations with 324 marker loci on 21 linkage groups covering a 1,352 cM genome distance (Qin et al. 2012).

Beside the effort towards development of integrated maps based on two or three individual maps, the marker density and number of markers has not been enhanced significantly. Therefore, a global effort was initiated to put maximum markers on the saine genetic map through integrating markers from all published individual genetic maps. Marker information from one BackCross (BC) population (Fonceka et al. 2009) was also included 


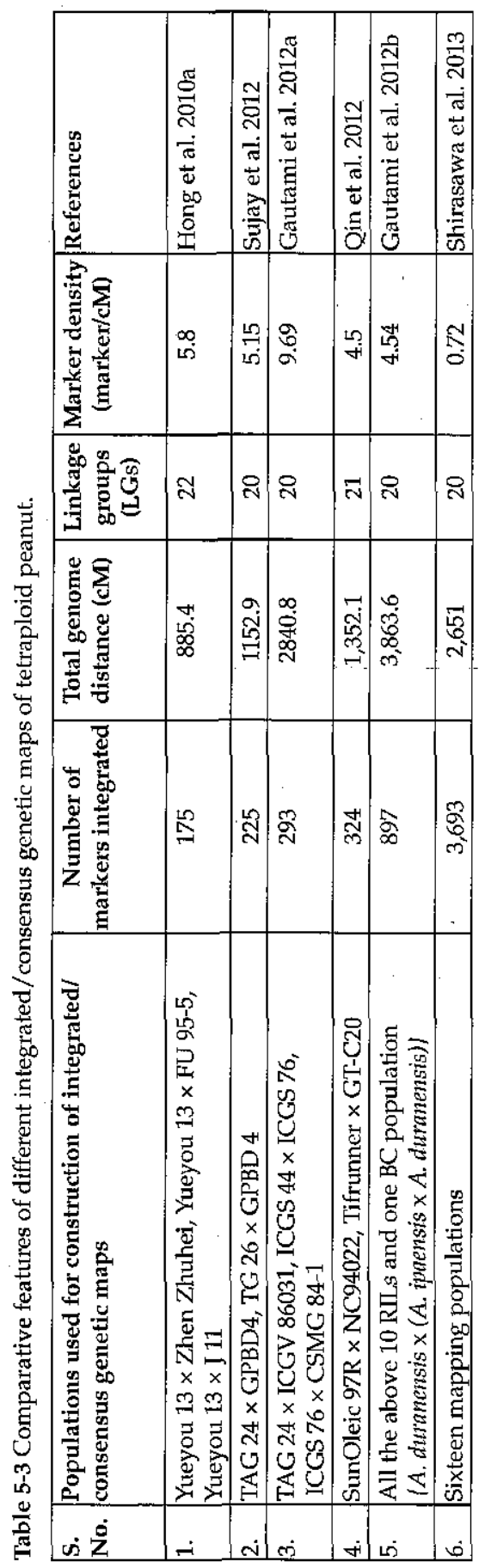


in the development of a reference consensus map along with 10 individual genetic maps, which were all constructed using RIL populations. Finally, the reference consensus genetic map was constructed with 897 marker loci. These 897 marker loci ( 895 SSRs and 2 CAPS) could be mapped on 20 linkage groups spanning a total map distance of $3,607.97 \mathrm{cM}$ with an average map density of $3.94 \mathrm{cM}$ (Gautami et al. 2012b). More interestingly, this reference consensus genetic map was divided into $20 \mathrm{cM}$ along with $203 \mathrm{BINs}$, which carry one to 20 loci with an average of four marker loci per BIN. Realizing the importance of dense consensus genetics maps, the above consensus genetic map has recently been improved further by international research partners. The mapping information from five new genetic maps (total 16 individual genetic maps) were utilized for improvement of an earlier consensus map from 897 to 3,693 markers spanning 2,651 cM of the genome and 20 linkage groups (Shirasawa et al. 2013). These dense consensus maps will have greater impact on peanut improvement because of their use in several applications such as aligning new genetic and physical maps, QTL analysis, genetic background effect on QTL expression and several other genetic and molecular breeding activities in peanut.

\subsection{Trait Mapping}

The ultimate goal of development of markers and genetic maps is to identify markers that are associated with traits of interest. Hence, denser genetic maps covering the full genome will enhance chances for identification of tightly-linked markers to agronomically important traits through linkage/ association mapping. That is why almost all the genetic maps (except Wang et al. 2012) were constructed using immortal RIL populations segregating for important traits in cultivated peanut. Once tightly linked/perfect/ functional markers are developed using these resources, these markers can be deployed in marker-assisted peanut improvement.

Initial mapping populations in peanut were developed in order to map the maximum number of loci on a single genetic map by selecting parents with diverse origins. Realizing the restricted use of these genetic maps in cultivated peanut improvement, later research focused on only development of mapping populations targeting mapping of economically important traits such as biotic stresses (TSWV, early leaf spot, late leaf spot, rust, aphid vector of groundnut rosette disease, Cylindrocladium black rot disease, Sclerotinia and nematode resistance), abiotic stress (drought tolerance), nutritional quality (aflatoxin contamination, oil content, oleic acid, linoleic acid, oleic/linoleic acid ratio) and several agronomic traits (Pandey et al. 2012a; Varshney et al. 2013a) (Table 5-4). The initial efforts towards mapping of economically important traits was through Bulked Segregant Analysis (BSA) for identifying the linked marker to nematode resistance (Burow et 


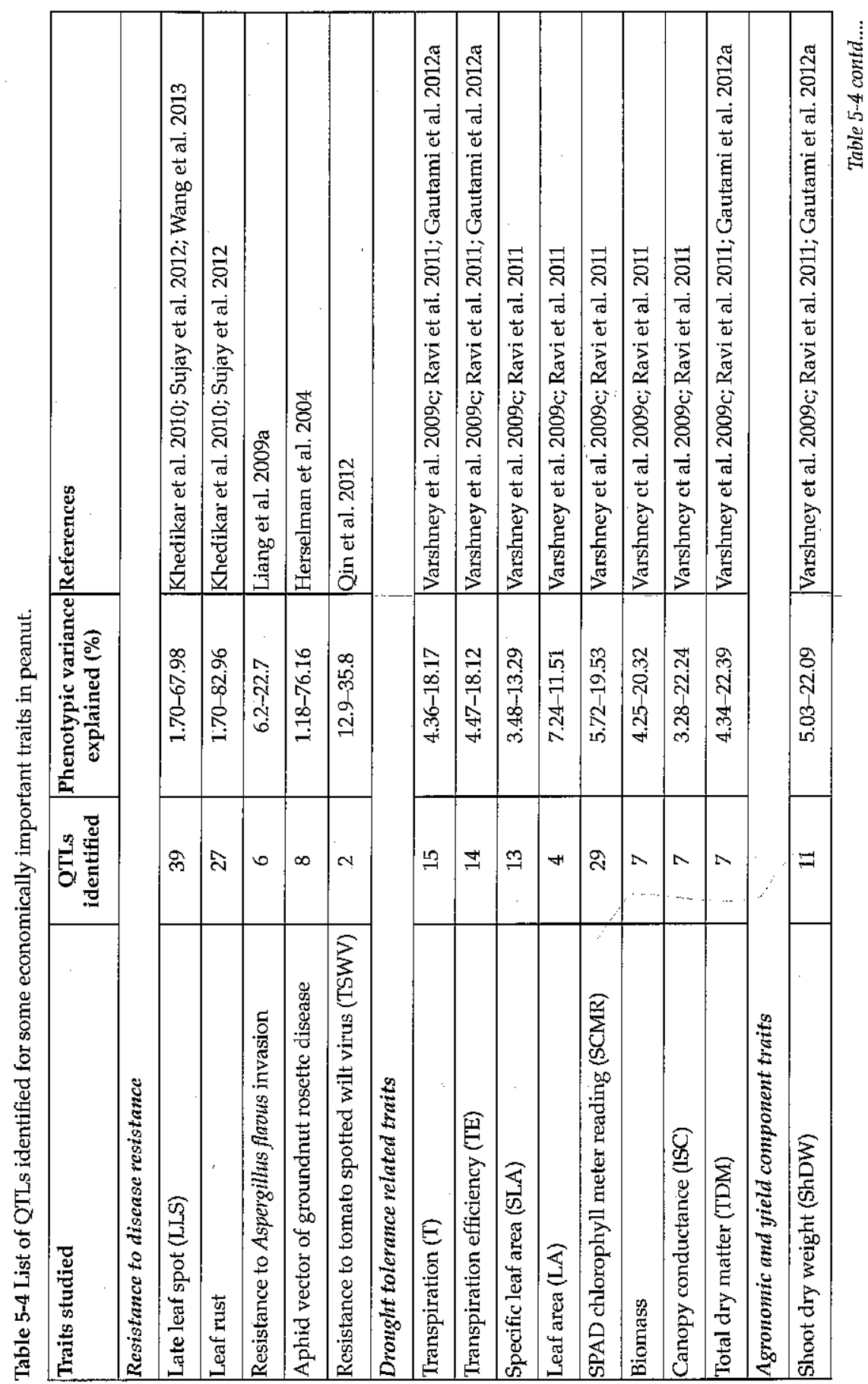




\begin{tabular}{|c|c|c|c|c|c|c|c|c|c|c|c|c|c|c|c|c|c|c|}
\hline 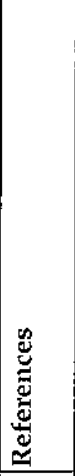 & 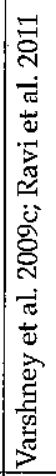 & 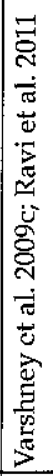 & 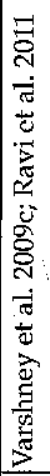 & 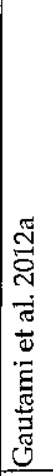 & 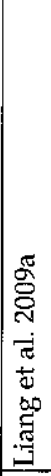 & 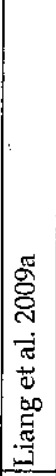 & 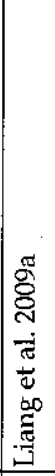 & 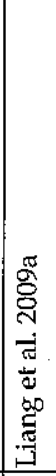 & 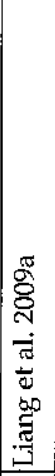 & 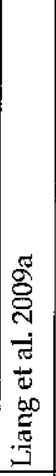 & 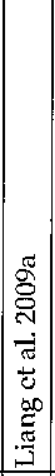 & 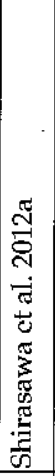 & 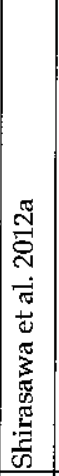 & 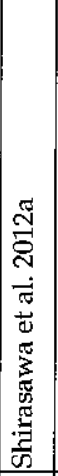 & 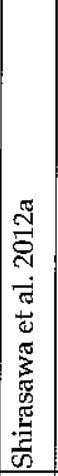 & 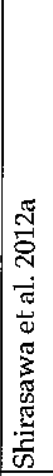 & 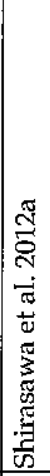 & 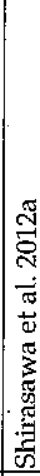 \\
\hline 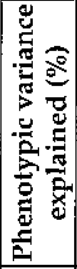 & 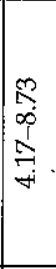 & 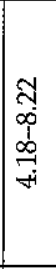 & 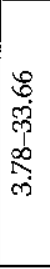 & $\begin{array}{l}0 \\
\stackrel{0}{1} \\
\stackrel{5}{7} \\
0 \\
0 \\
0 \\
0\end{array}$ & 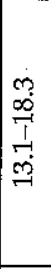 & 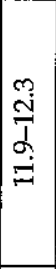 & $\begin{array}{c}- \\
\stackrel{3}{2} \\
\stackrel{1}{1} \\
\stackrel{1}{\infty} \\
\infty\end{array}$ & $\stackrel{10}{10}$ & 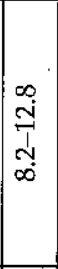 & 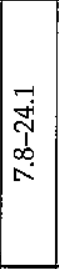 & 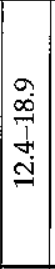 & 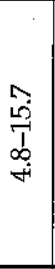 & 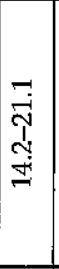 & 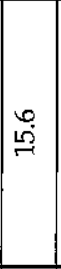 & $\stackrel{\infty}{=}$ & $\vec{\infty}$ & 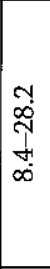 & $\vec{\sim}$ \\
\hline 要 & $\Delta$ & 10 & 0 & $\infty$ & $\infty$ & $\infty$ & $\pi$ & $m$ & $n$ & 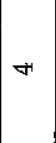 & $\infty$ & $m$ & $N$ & -1 & - & - & $m$ & -1 \\
\hline 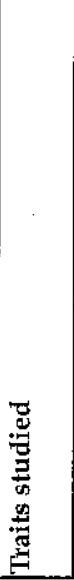 & 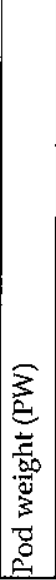 & 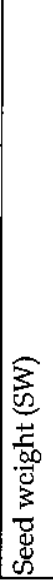 & 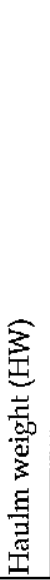 & 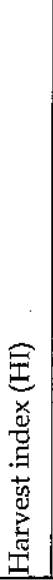 & 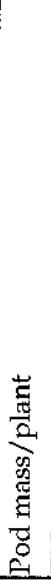 & 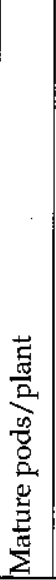 & 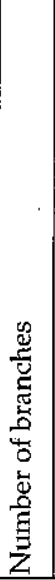 & 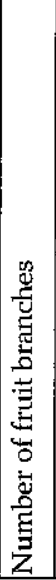 & 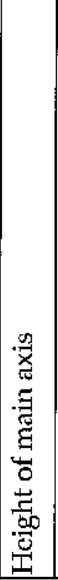 & 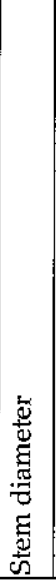 & 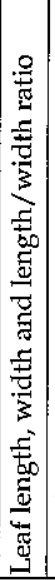 & 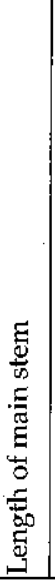 & 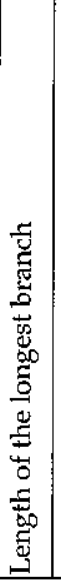 & 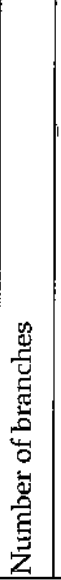 & 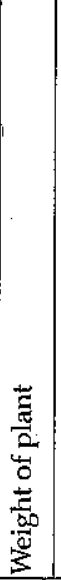 & 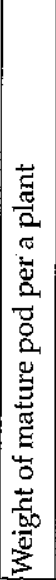 & 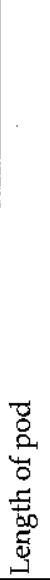 & 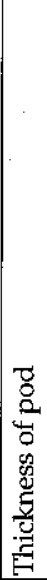 \\
\hline
\end{tabular}




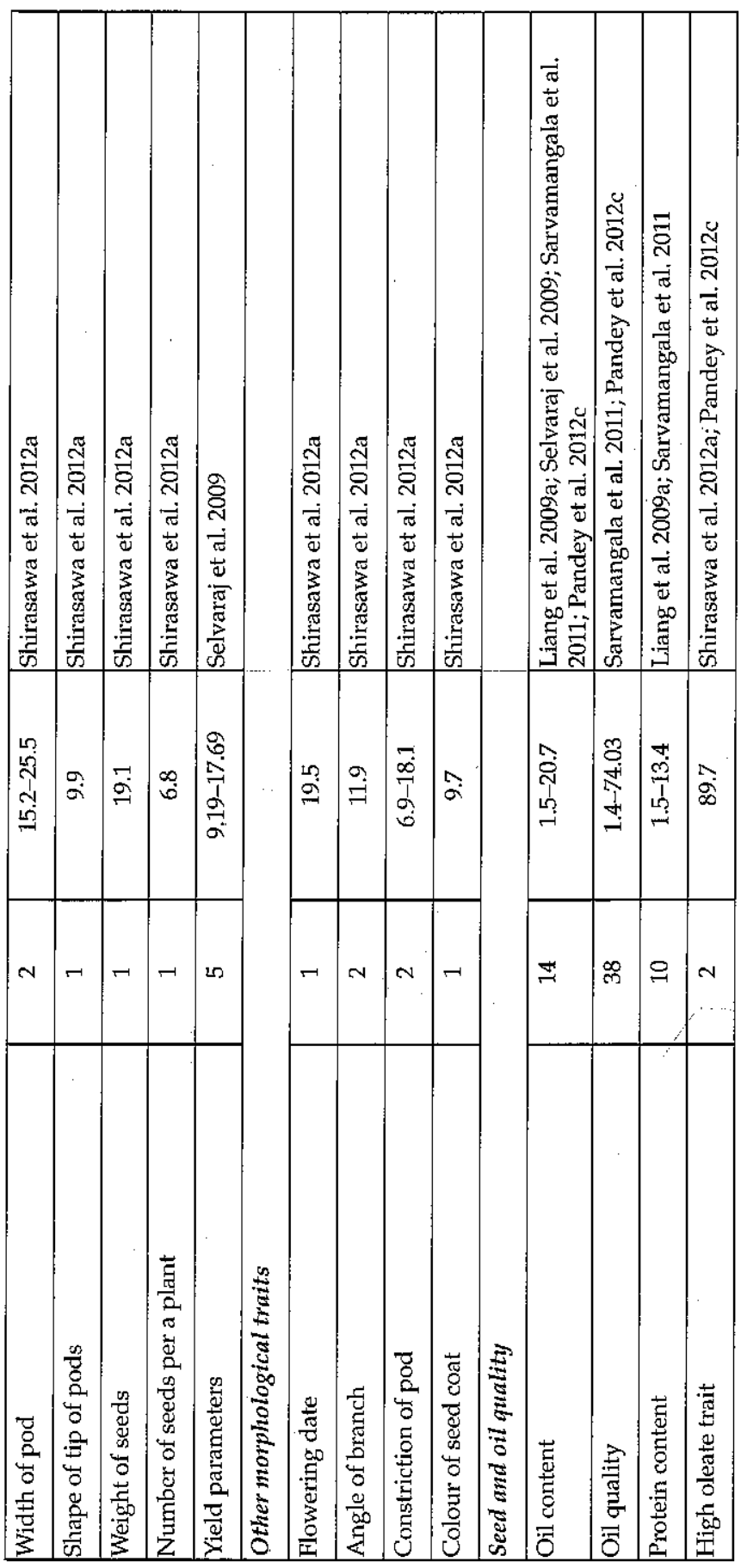


al. 1996; Garcia et al. 1996) and aphid vector of groundnut rosette disease (Herselman et al. 2004) using RAPD and AFLP markers, respectively. Similarly, the above strategy was also used for mapping the yield and yield components with SSR markers (Liang et al. 2009a; Selvaraj et al. 2009). The above mapping strategy is relatively simpler to use in crops lacking genomic resources and also for simply-inherited traits. Hence, with the availability of more SSR markers in public domains, a major shift was observed towards development of immortal populations in order to generate multiseason phenotyping data so that stable QTLs can beidentified along with studying $\mathrm{G} \times \mathrm{E}$ interactions using advanced mapping tools. Such studies were conducted to identify the QTLs for drought tolerance related traits (Varshney et al. 2009c; Ravi et al. 2011; Gautami et al. 2012a), resistance to biotic resistance (Khedikar et al. 2010; Pandey et al. 2012c; Qin et al. 2012; Sujay et al. 2012; Wang et al. 2013), morphological and yield components (Varshney et al. 2009; Pandey et al. 2012c; Shirasawa et al. 2012a) and nutritional quality traits (Sarvamangala et al. 2011; Pandey et al. 2012c; Shirasawa et al. 2012a).

Three mapping populations (TAG $24 \times$ ICGV 86031, ICGS $44 \times$ ICGS 76, ICGS $76 \times$ CSMG 84-1) were used for identification of QTLs controlling drought-tolerance related traits (Varshney et al. 2009c; Ravi et al. 2011; Gautami et al. 2012a) and mapping of all the identified QTLs onto an integrated genetic map (Gautami et al. 2012a). Multiseason phenotypic data were generated on these populations for drought-tolerance related traits such as transpiration, transpiration efficiency, biomass, specific leaf area, pod weight, total dry matter, SPAD chlorophyll meter reading, total dry weight, shoot dry weight and harvest index traits. Simultaneously, genotypic data were generated on these three mapping populations followed by construction of individual genetic maps with mapped loci ranging from 82 (ICGS $44 \times$ ICGS 76) to 191 (TAG $24 \times$ ICGV 86031) marker loci. Different QTL mapping programs such as QTL Cartographer, QTL Network and Genotype Matrix Mapping (GMM) were used for detailed QTL analysis using genotyping and multiseason phenotyping data. This analysis resulted in identification of a total of 153 main effects! and 25 epistatic QTLs for drought-tolerance related traits (Varshney et al. 2009c; Ravi et al. 2011; Gautami et al. 2012a). In addition, 16 important genomic regions on the integrated maps were identified realizing their potential role towards drought tolerance (Table 5-4). The above study revealed that the majority of the identified QTLs contributed low phenotypic variation, and hence, molecular breeding approaches such as Marker-Assisted Back Crossing $(\mathrm{MABC})$ will not be useful for introgressing drought tolerance. In order to handle such QTLs, other modern breeding approaches (marker-assisted recurrent selection and genomic selection) may be more appropriate. 
Another notable QTL study was conducted for mapping QTLs for resistance to foliar diseases such as late leaf spot (LLS) and rust (Khedikar et al. 2010; Sujay et al. 2012). Two RIL populations, namely TAG $24 \times$ GPBD 4 and TG $26 \times$ GPBD 4, were extensively phenotyped for rust and LLS resistance for seven to eight seasons. Genotyping data were generated for 209 polymorphic markers for each of the two populations. Two individual genetic maps with 188 (TAG $24 \times$ GPBD 4) and 181 (TG $26 \times$ GPBD 4) marker loci were constructed along with development of an integrated map with 225 marker loci. Using the multiseason phenotyping data and genotyping information, a comprehensive QTL analysis identified a total of 28 QTLs for resistance against late leaf spot (LLS) and 13 QTLs for resistance against rust explaining 10.07 to $67.8 \%$ and 2.54 to $82.96 \%$ of phenotypic variation, respectively (Khedikar et al. 2010; Sujay et al. 2012). This study led to the identification of tightly linked markers and one major QTL each for leaf rust (55.2\% PVE, Khedikar et al. 2010; 82.96\% PVE, Sujay et al. 2012) and LLS (67.98\% PVE, Sujay et al. 2012) resistance (Table 5-4). The tightly linked markers for rust resistance (IPAHM103, GM2079, GM2301 and GM1536) were identified in both the populations and were then validated among a set of resistant/susceptible breeding lines. Furthermore, phenotypic data on oil content and quality were also generated on one of these RIL populations (TG $26 \times$ GPBD 4) to identify linked markers for important nutritional traits. QTL analysis using phenotypic data and partial genetic map information detected seven QTLs for protein content (2.54-9.78\%), eight QTLs for oil content (1.5-10.2\%) and six common QTLs for oleic and linoleic acid contents (3.3-9.7\%) (Sarvamangala et al. 2011).

The next effort towards trait mapping was to identify linked markers for tomato spotted wilt virus (TSWV) resistance using two RIL populations, namely $\mathrm{T}$ (Tifrunner $\times$ GT-C20) and S (SunOleic 97R $\times$ NC 94022), populations. Genotyping data of both the maps were used for construction of an integrated map and identification of QTLs for TSWV resistance. QTL analysis using QTL Cartographer detected one QTL in each of the two populations with PVE ranging from 12.9 (qTSWV1) to 35.5\% (qTSWV2) (Qin et al. 2012). The linked markers (IPAHM287 and Seq12F7) need validation before applying in routine MAS programs. Most recently, Shirasawa et al. (2012a) reported identification of QTLs for several agronomic traits for which PVE ranged from $11.8 \%$ (plant weight and angle of branch) to $28.2 \%$ (pod length). The other traits (PVE\%) for which QTLs have been reported include flowering date (19.5\%), length of main stem (15.7-19.2\%), length of longest branch (14.2-21.1\%), number of branches (15.6\%), mature pod weight/plant $(28.1 \%)$, pod thickness $(21.7 \%)$, pod width $(15.2-25.5 \%)$, pod constriction (18.1\%), seed weight $(19.1 \%)$ and seed diameter $(24.1 \%)$.

Attempts were also made to identify linked markers from wide crosses for nematode resistance and as a result, two SCAR markers (Garcia et al. 
1996) and three RAPD markers (Burow et al. 1996) were identified using the populations (A. hypogaea $\times$ A. cardenasii) and (A. hypogaea $\times \mathrm{T} x \mathrm{AG}-6)$, respectively. Since these markers produced inconsistent results and were complicated to use in routine molecular breeding programs, the RAPD marker (RKN440, Garcia et al. 1996) was converted into a new PCRbased dominant marker (S197) (Chu et al. 2007a). Nagy et al. (2010b) also identified a total of 13 markers (including S197 reported by Chu et al. 2007a) in two tetraploid crosses. A total of three markers namely S197 (PCRbased), 1169/1170 (CAPS) and GM565 (SSR) were used to select resistant, susceptible and heterozygous allele, respectively during development of the second marker-assisted product in peanut, i.e., Tifguard High O/L (Chu et al. 2011). Another study with diploids resulted in the identification of five QTLs for resistance to LLS from the cross A. duranensis $\times$ A. stenosperma (Leal-Bertioli et al. 2009). Initially, CAPS markers were developed for mutant FAD alleles in both genomes (Chu et al. 2009), but later PCR-based allele-specific markers were reported by the same research group (Chu et al. 2011). These allele-specific markers are now successfully mapped on the peanut genome along with identification of a total of 155 QTLs for oil quality and several agronomically important traits. QTL analysis also revealed that the $F A D 2 B$ gene contributes more than the $F A D 2 A$ gene for high oleic/linoleic (O/L) ratio (Pandey et al. 2012c). Further, very high PVE $(65.20-89.7 \%)$ has been reported for high oleate traits (Pandey et al. 2012c; Shirasawa et al. 2012a).

Although linked markers to a few disease resistance traits such as nematode (Nagy et al. 2010b), leaf rust (Khedikar et al. 2010; Sujay et al. 2012), LLS (Sujay et al. 2012) and TSWV (Qin et al. 2012) and one oil quality trait, i.e., high-oleate trait (Chu et al. 2009; Chen et al. 2010; Pandey et al. 2012c; Shirasawa et al. 2012a) are currently available to use in molecular breeding, more research is needed for identifying tightly-linked molecular markers to several other important traits. It is anticipated that the availability of more genomic resources, such as SNPs, and the genome sequence will accelerate trait mapping efforts in the near future and will make available linked markers for many other traits (Varshney et al. 2012).

\subsection{Genomics-assisted Breeding}

Genomics-assisted breeding (GAB) offers a breeding platform where genomics tools are integrated with conventional breeding methods to develop improved genotypes, in a very short time, for several traits / genes at once and is also able to minimize the inhibited fear of linkage drag in wide crosses (Varshney et al. 2006). GAB, mainly marker-assisted breeding has achieved only limited success in peanut, and even that has been restricted to simply-inherited traits. The majority of agronomically important traits 
are complex in nature and governed by several genomic regions, which also show interactions with environments $(G \times E)$ and other genomic regions (epistasis). Hence, genomics tools along with modern decision making tools should be used along with proven conventional breeding approaches to understand the exact genetic nature of the target traits and for finding ways for their possible manipulation leading to genetic enhancement.

Currently, GAB could be used for crop improvement in three ways, i.e., marker-assisted backcrossing (MABC), Marker-Assisted Recurrent Selection (MARS) and Genomic Selection (GS). The first two approaches require QTL information, while the 3rd one does not. In practice, introgression of recessive genes and pyramiding of multiple genes is very difficult, costly, lengthy and error prone using conventional breeding methods. Markerassisted selection (MAS) has proved its utility in several crops to overcome such problems and many genes can be pyramided either for the same trait or for different traits along with faster recurrent parent genome recovery through intense background selection (Varshney et al. 2006). In addition, MAS can be used to pyramid/introgress several recessive genes in less time and with more precision, which is almost impossible through conventional breeding. MAS has gained popularity due to its proven record-in several crops and is easy to use even in smaller research stations that have low to moderate marker genotyping capabilities. In peanut, these tools have been integrated into the conventional breeding programs very late due to the lack of genomic resources such as molecular markers, genetic maps and most importantly tightly-linked markers for the most desirable traits in peanut. Nevertheless, some efforts have been made to use molecular markers in peanut breeding.

Root-knot nematode (Meloidogyne arenaria) resistance, the first trait for which linked molecular markers were identified, was introgressed from A. cardenasii through the amphidiploid pathway into cultivated peanut (Simpson 2001). This was relatively easy to identify due to sequence divergence between diploid and tetraploid genomes (Chu et al. 2007a; Nagy et al. 2010b). This effort led to the development of the first MAS product in peanut, named as NemaTAM (Simpson et al. 2003), the first peanut cultivar developed using MAS. MAS has shown several benefits in the development of "NemaTAM" such as selection of heterozygous and homozygous plants in early generations with very high precision at the seedling stage. Phenotyping for nematode resistance is prone to environmental fluctuations and more often leads to escapes (Simpson et al. 2003).

The RFLP marker system used to develop NemaTAM is very costly, requires DNA in large quantity, entails health risk due to the use of radioisotopes, also requires high technical expertise and has a long turnaround time for results. Since breeders require timely genotyping information to make backcrosses, efforts were made to develop more 
rapid and easy-to-assay markers for nematode resistance (Nagy et al. 2010b). Meanwhile, a tightly associated CAPS marker (1101/1048) became available for another important trait, i.e., high oleic acid (Chu et al. 2009). The associated markers for high oleic acid were deployed to backcross the high-oleate trait $(F A D 2 B)$ into the nematode resistant cultivar, Tifguard (Holbrook et al. 2011). Homozygous recessive mutations in both AhFAD2 homeologs are necessary to achieve high $\mathrm{O} / \mathrm{L}$. Since the frequency of a spontaneous loss-of-function allele of $A h F A D 2 A$ is high in the ssp. hypogaea germplasm (Chu et al. 2007b) and fixed in most elite lines of US runner and Virginia market-type peanuts (Chu et al. 2009), therefore, MAS was required only to select the mutant allele of $A h F A D 2 B$ for making Tifguard High O/L. Markers linked with nematode resistance were used to monitor flow of the nematode-resistant allele in backcross and selfed generations. These markers have been used during $M A B C$ to select desired DNA fragment carrying nematode resistance while simultaneously selecting for a recessive $A h F A D 2 B$ allele necessary to recover lines with a high ratio of oleic:linoleic acid $(\mathrm{O} / \mathrm{L})$ leading to development of the 2nd MAS product in peanut namely, "Tifguard High O/L" (Chu et al. 2011).

Development of immortal populations and generation of multiseasonal phenotypic data resulted in the identification of stable QTLs and tightlylinked molecular markers for LLS and leaf rust (Khedikar et al. 2010; Sujay et al. 2012). The linked markers for leaf rust were deployed to introgress leaf rust resistance into the genetic background of three elite cultivars (ICGV 91114, JL 24 and TAG 24) through MABC at ICRISAT, India. An important result of this study was identification of SSR markers, which are easy to genotype even in smaller laboratories. Three codominant markers (GM2079, GM2301 and GN1536) and one dominant SSR marker (IPAHM103) were used to select heterozygous allele at backcrossed $\mathrm{F}_{1}\left(\mathrm{BC}_{1} \mathrm{~F}_{1}, \mathrm{BC}_{2} \mathrm{~F}_{1}\right.$ and $\left.\mathrm{BC}_{3} \mathrm{~F}_{1}\right)$ generations and homozygous allele at backcrossed $\mathrm{F}_{2}\left(\mathrm{BC}_{2} \mathrm{~F}_{2}\right.$ and $\left.\mathrm{BC}_{3} \mathrm{~F}_{2}\right)$ generations. As a result, a total of 200 advanced generation introgression. lines $\left(117 \mathrm{BC}_{2} \mathrm{~F}_{5}\right.$ and $83 \mathrm{BC}_{3} \mathrm{~F}_{5}$ ) were developed using the above markers for all the above three elite cultivars. Superior lines with desirable yield and higher resistance to leaf rust were selected based on replicated evaluation during the rainy seasons in 2011 and 2012 for further multiplication and multilocation trails (Varshney et al. 2013b). The initial screening has been very encouraging showing reduced disease symptoms and has led to the identification of several promising lines in all the three genetic backgrounds. However, in the case of drought tolerance, many QTLs were identified each contributing only small phenotypic variance (Varshney et al. 2009c; Ravi et al. 2011; Gautami et al. 2012a). In such cases, MABC approach may not be appropriate and hence, other modern breeding approaches such as MARS or GS might be better approaches (Bernardo and Yu 2007; Ribaut and Ragot 2007; Bernardo 2009; Heffner et al. 2009; Jannink et al. 2010). 
Apart from three traits (nematode resistance, high oleate and leaf rust) discussed above, QTLs and linked markers for two more diseases namely LLS (Sujay et al. 2012) and TSWV (Qin et al. 2012) have been reported. These markers linked to LLS (GM1573/GM1009 and Seq8D09) and TSWV (IPAHM287 and Seq12F7) provide hope for marker-assisted improvement of resistance to these two diseases in the near future. The future of GAB in peanut may be more fruitful due to increased availability of linked markers to other important traits of peanut which will accelerate multiple trait improvement of existing high yielding cultivars and development of new cultivars through gene pyramiding.

\subsection{Diversification and Enrichment of Primary Gene Pool}

Tetraploidization has restricted gene flow from diploids to tetraploid (cultivated) which has created a serious genetic bottleneck. Efforts into making wide crosses through use of hexaploids, autotetraploids and allotetraploids have been plagued by serious problems with fertility barriers, linkage drag and difficulty in tracking introgressed alien genomic regions (Bertioli etal. 2011). Of these three-barriers, two (linkage drag and trackingalien genomic regions) can be efficiently handled by integrating genomics into routine breeding programs to diversify the narrow peanut primary gene pool. GAB can help in tracking alien genomic regions and hence, linkage drag can be minimized. Several efforts have attempted to introgress wild genes into cultivated, most involving disease resistance (Simpson 1991; Singh 1996; Tansley and Nelson 1996; Stalker et al. 2002; Favero et al. 2006; Fonceka et al. 2009; Leal-Bertioli et al. 2011; Mallikarjuna et al. 2011).

Introgressing useful alleles from wild relatives can be done with higher precision using genomics and decision making tools. Molecular markers evenly distributed throughout genomes have been utilized for tracking genome recovery during backcrossing in several crops. While introgressing genes from wild relatives, stringent background selection is required using markers covering the full genome to avoid linkage drag from unwanted genomic segments from wild relatives. The lone effort towards alien genomic introgressions made using this approach in peanut was with the use of limited genomic resources by Fonceka et al. (2009). A synthetic amphidiploid (A. duranensis $\times A$. ipaënsis) was used to cross with a cultivated variety (Fleur 11) followed by two backcrosses. Molecular markers were used to track alien genomic region introgressions in the genetic background of the cultivated genotype "Fleur 11 " in backcross generations. This facilitated selection of several introgression lines with varied amounts of wild genomic segments for further study. With the availability of more genomic resources and high throughput genotyping platforms, it will become easier to broaden the 
genetic base of the primary gene pool by introgressing genomic segments from the wild species or synthetic amphidiploid genotypes with the help of molecular markers.

\subsection{Towards Assembling the Genome Sequence}

Recent advances in Next-Generation Sequencing (NGS) technology platforms have enabled much-needed faster sequence data generation along with advancements in informatics and assembly tools to manage and analyze NGS data (Varshney and May 2012). Before recent advances in technology whole-genome sequencing of crops with larger genome size and complex genomes was questionable. The main problem now lies in analyzing and transmission of information to apply for crop improvement through discovery of genes, and molecular markers associated with economically important traits (Edward and Baitley 2010). Using advanced technologies, whole genomes have been sequenced for several crop species but sequencing of the peanut genome has not been accomplished due to its large size, which is 20-times larger than that of Arabidopsis thaliana, and 2-6times larger than that of rice, sorghum or soybean. Nevertheless, sequencing for the peanut genome has been initiated by the Peanut Genome Consortium (PGC) http:/ /www.peanutbioscience.com/peanutgenomeproject.html) for the tetraploid cultivar "Tifrunner". The Peanut Genome Project (PGP) is initiating sequencing of the peanut genome in collaboration with BGIShenzhen (China). It is, therefore, anticipated that a draft genome sequence along with extensive genome and trancriptome information will be available for the peanut research community within the near future. The genome sequence data will lead to the identification of several hundred molecular markers leading to the development of dense genetic maps, which will facilitate identification of linked/associated markers with economically important traits to use in genetic enhancement of cultivated peanut.

\subsection{Summary and Future Prospects}

GAB should accelerate genetic enhancement leading to improved productivity, oil quality and resistance/tolerance to stresses. Recent advances have resulted in the development of SSR markers and several genetic maps for different genomes ( $\mathrm{AA}, \mathrm{BB}, \mathrm{AABB}$ genomes). The density of genetic maps in diploid (AA and $B B$ ) genomes was higher than the tetraploid genetic maps. Even though the tetraploid species has both the genomes, the genetic diversity observed in cultivated maps has been low. Therefore, only partial ( $<100$ loci) to low-moderate ( $<300$ loci) genetic maps could be constructed. One of the major challenges was to integrate as many markers as possible on a single genetic map, which was solved through 
successful development of a reference consensus genetic map with 897 marker loci based on 11 individual genetic maps. Now, the expectation lies with SNP markers to develop high density genetic maps but it will take few years before these markers are in routine use for breeding and genetic applications. Until that time, SSR markers are going to continue to be used in genetic and breeding applications in cultivated peanuts. Efforts with the available limited genomic resources led to the identification of linked markers for oil quality (high oleic acid) and disease resistance (nematode, rust, LLS and TSWV) traits in cultivated peanut through trait mapping. These developments also led to the deployment of linked markers to improve disease resistance and oil quality through MABC approaches. It is now feasible to pyramid resistance to all the four diseases along with the high oleic trait. Further attention is required towards other challenging areas such as drought stress along with aflatoxin/mycotoxin contamination, which has teratogenic and carcinogenic effects on humans and animals. The expected availability of genome sequence in the near future should provide huge genomic resources, which will hasten the efforts of the muchneeded linking of phenotype with markers/genome sequences. However, it can only be achieved with precise and high-throughput phenotyping for complex traits. Recent advances in peanut genomics and molecular breeding efforts provide hope for efficient genetic enhancement of cultivated peanut to address different production as well as quality constraints.

\section{Acknowledgements}

The authors are grateful to the National Fund of the Basic and Strategic Research in Agriculture (NFBSRA) of the Indian Council of Agriculture Research (ICAR), New Delhi, India, Generation Challenge Program (http:/ /www.generationcp.org) of CGIAR, Department of Biotechnology, Government of India for Center of Excellence (CoE) grant, The Peanut Foundation, USA, Georgia Peanut Commission, USA and National Peanut Board, USA for supporting work of several authors presented in this article.

\section{Abbreviations}

CAAS (China) : Chinese Academy of Agricultural Sciences

CENARGEN (Brazil) : National Research Center for Genetic Resources and Biotechnology

CRI (China)

DGR (India)

Crops Research Institute

EMBRAPA (Brazil)

GAAS (China)

Directorate of Groundnut Research

Brazilian Agricultural Research Corporation

Guangdong Academy of Agricultural Sciences 


\begin{tabular}{|c|c|c|}
\hline ONE (Argen & & heast \\
\hline ICAR (India) & : & Indian Council of Agricultural Research \\
\hline ICRISAT (India) & & $\begin{array}{l}\text { International Crops Research Institute for the } \\
\text { Semi-Arid Tropics }\end{array}$ \\
\hline INTA (Brazil) & & $\begin{array}{l}\text { Argentina Agronomic Institute of Campinas in } \\
\text { Brazil; and Instituto Nacional de Agropecuaria }\end{array}$ \\
\hline NBPGR (India) & & National Bureau of Plant Genetic Resources \\
\hline NCSU (USA) & & North Carolina State University \\
\hline OCRI (China) & & Oil Crops Research Institute \\
\hline TAMU (USA) & & Texas A \& M University \\
\hline USDA (USA) & & U.S. Department of Agriculture \\
\hline
\end{tabular}

\section{References}

Beavis WD, Grant D (1991) A linkage map based on information from four $F_{2}$ populations of maize (Zea mays L.). Theor Appl Genet 82: 636-644.

Bernardo R, Yu J (2007) Prospects for genome wide selection for quantitative traits in maize. Crop Sci 47: 1082-1090.

Bernardo R (2009) Genome wide selection for rapid introgression of exotic germplasm in maize. Crop Sci 49: 419-425.

Bertioli DJ, Seijo G, Freitas FO, Valls FM, Leal-Bertioli SCM, Moretzsohn (2011) An overview of peanut and its wild relatives. Plant Genetic Resour: Characteriz Utiliz 9: 134-149.

Bohra A, Saxena RK, Gnanesh BN, Saxena K, Byregowda M, Rathore A, Kavikishore PB, Cook DR, Varshney RK (2012) An intra-specific consensus genetic map of pigeonpea [Cajanus cajon (L.). Millspaugh] derived from six mapping populations. Theor Appl Genet 125: 1325-38.

Bravo JP, Hoshino AA, Angelici CMLCD, Lopes CR, Gimenes MA (2006) Transferability and use of microsatellite markers for the genetic analysis of the germplasm of some Arachis section species of the genus Arachis. Genet Mol Biol 29: 516-524.

Burow MD, Simpson CE, Paterson AH, Starr JL (1996) Identification of peanut (Arachis. hypogaea L.) RAPD markers diagnostic for root-knot nematode (Meloidogyne arenaria (Neal) Chitwood) resistance. Mol Breed 2: 369-379.

Burow MD, Simpson CE, Starr JL, Paterson AH (2001) Transmission genetics of chromatin from a synthetic amphiploid in cultivated peanut (A. hypogaea L.): Broadening the gene pool of a monophyletic polyploid species. Genetics 159: 823-837.

Chen Z, Wang ML, Barkley NA, Pittman RN (2010) A simple allele-specific PCR assay for detecting FAD2 alleles in both $\mathrm{A}$ and $\mathrm{B}$ genomes of the cultivated peanut for high-oleate trait selection. Plant Mol Biol Rep 28: 542-548.

Choi IY, Hyten DL, Matukumalli LK, Song Q, Chaky JM, Quigley CV, Chase K, Lark KG, Reiter RS, Yoon M-S, Hwang E-Y, Yi S-I, Young ND, Shoemaker RC, van TasselI CP, Specht JE, Cregan PB (2007) A soybean transcript map: gene distribution, haplotype and singlenucleotide polymorphism analysis. Genetics 176: 685-696.

Chx Y, Holbrook CC, Timper P, Ozias-Akins P (2007a) Development of a PCR-based molecular marker to select for nematode resistance in peanut. Crop Sci 47: 841-845.

Chu Y, Ramos L, Holbrook CC, Ozias-Akins P (2007b) Frequency of a loss-of-function mutation in oleoyl-PC desaturase ( $a h F A D 2 A)$ in the minicore of the U.S. peanut germplasm collection. Crop Sci 47: 2372-2378.

Chu Y, Holbrook CC, Ozias-Akins P (2009) Two alleles of ahFAD2B control the high oleic acid trait in cultivated peanut. Crop Sci 49: 2029-2036. 
Chu Y, Wu CL, Holbrook CC, Tillman BL, Person G, Ozias-Akins P (2011) Marker-assisted selection to pyramid nematode resistance and the high oleic trait in peanut. Plant Genome 4: 110-117.

Cuc LM, Mace ES, Crouch JH, Quang VD, Long TD, Varshney RK (2008) Isolation and characterization of novel microsatellite markers and their application for diversity assessment in cultivated groundnut (Arachis hypogaea). BMC Plant Biol 8: 55.

Dwivedi SL, Gurtu S, Chandra S, Weng YJ, Nigam SN (2001) Assessment of genetic diversity among selected groundnut germplasm-I: RAPD analysis. Plant Breed 120: 345-349.

Edwards D, Batley J (2010) Plant genome sequencing: applications for crop improvement. Plant Biotechnol J 8: 2-9.

Falque M, Décousset L, Dervins D, Jacob AM, Joets J, Martinant J-P, Raffoux X, Ribière N, Ridel C, Samson D, Charcosset A, Murigneux A (2005) Linkage mapping of 1454 maize candidate gene loci. Genetics 70: 1957-1966.

Fávero AP, Simpson CE, Valls JFM, Valls NA(2006) Study of the evolution of cultivated peanut through crossability studies among Arachis ipaënsis, A. duranensis, and A. hypogaea. Crop Sci 46: $1546-1622$.

Ferguson ME, Burow MD, Schultze SR, Bramel PJ, Paterson AH, Kresovich S, Mitchell S (2004) Microsatellite identification and characterization in peanut (A. hypogaea L.). Theor Appl Genet 108: 1064-1070.

Foncéka D, Hodo-Abalo T, Rivallan R, Faye I, Sall MN, Ndoye O, Fávero AP, Bertioli DJ, Glaszmann JC, Courtois B, Rami JF (2009) Genetic mapping of wild introgressions into cultivated peanut: a way toward enlarging the genetic basis of a recent allotetraploid. BMC Plant Biol 9: 103.

Froenicke L, Pandey M, Upadhyaya $\mathrm{H}$, Moretzsohrn MC, Guimarães P, Leal-Bertioli S, Varshney RK, Bertioli D, Michelmore RW (2011) Towards ultra-dense genetic maps of peanut generated by sequencing diploid and tetraploid $\mathrm{RL}$ populations and a peanut diversity panel. In: Proc Advances in Arachis through Genomics and Biotechnology (AAGB), 13-15 June 2011, Brasilia, Brazil.

Garcia GM, Stalker HT, Kochert G (1995) Introgression analysis of an interspecific hybrid population in peanuts (Arachis hypogaea L.) using RFLP and RAPD markers. Genome 38: 166-176.

Garcia GM, Stalker HT, Shroeder E, Kochert G (1996) Identification of RAPD, SCAR and RFLP markers tightily linked to nematode resistance genes introgressed from Arachis cardenasii to A. hypogaea. Genome 39: 836-845.

Garcia GM, Stalker HT, Schroeder E, Lyerly JH, Kochert G (2005) A RAPD-based linkage map of peanut based on a backcross population between the two diploid species Arachis stenosperma and A. cardenasii. Peanut Sci 32: 1-8.

Gautami B, Ravi K, Narasu ML, Hoisington DA, Varshney RK (2009) Novel set of groundnut SSR markers for germplasm analysis and inter-specific transferability. Int J Integr Biol 7: 100-106.

Gautami B, Pandey MK, Vadez V, Nigam SN, Ratnakumar P, Krishnamurthy L, Radhakrishnan T, Gowda MVC, Narasu ML, Hoisington DA, Knapp SJ, Varshney RK (2012a).QTL analysis and consensus genetic map for drought tolerance traits based on three RIL populations of cultivated groundnut (Arachis hypogaea L.). Mol Breed 32: 757-772.

Gautami B, Fonceka D, Pandey MK, Morezsohn MC, Sujay V, Qin H, Hong Y, Faye I, Chen X, Bhanuprakash A, Shah TM, Gowda MVC, Nigam SN, Liang X, Hoisington DA, Guo B, Bertioli DJ, Rami JF, Varshney RK (2012b) An international reference consensus genetic map with 897 marker loci based on 11 mapping populations for tetraploid groundnut (Arachis hypogaea L.). PLoS ONE 7: e41213.

Gentzbittel L, Vear F, Zhang YX, Breville A, Nicolas P (1995) Development of a consensus linkage RFLP map of cultivated sunflower (Hetianthus annus L.). Theor Appl Genet 90: 1079-1086. 
Gimenes MA, Hosino AA, Barbosa AVG, Palmieri DA, Lopes CR (2007) Characterization and transferability of microsatellite markers of cultivated peanut (Arachis hypogaea). BMC Plant Biol 7: 9.

Gobbi A, Teixeira C, Moretzsohn M, Guimarães P, Leal-Bertioli SC, Bertioli D, Lopes CR, Gimenes M (2006) Development of a linkage map to species of $B$ genome related to the peanut (Arachis hypogaea-AABB). In: Proc Plant Anim Genome XIV Conf, 14 -18 Jan 2006, San Diego, USA, p 679.

Guo BZ, Fedorova ND, Chen X, Wan CH, Wang W, Nierman WC, Bhatnagar D, YuJ (2011) Gene expression profiling and identification of resistance genes to Aspergillus flavus infection in peanut through EST and microarray startegies. Toxins 3: 737-753.

Guo Y, Khanal S, Tang S, Bowers JE, Heesacker AF, Khalilian N, Nagy ED, Zhang D, Taylor CA, Stalker HT, Ozias-Akins P, Knapp SJ (2012) Comparative mapping in intraspesific populations uncovers high degree of macrosynteny between A- and B-genome diploid species of peanut. BMC Genomics 13: 608.

Gupta PK, Kumar J, Mir RR, Kumar A (2010) Marker-assisted selection as a component of conventional plant breeding. Plant Breed Rev 33: 145-217.

Halward TM, Stalker HT, Kochert G (1993) Development of an RFLP linkage map in diploid peanut species. Theor Appl Genet 87: 379-384.

Hauge BM, Hanley SM, Cartinhour S, Cherry JM, Goodman HM (1993) An integrated genetic/ RFLP map of the Arabidopsis thaliana genome. Plant J 3: 745-754.

He GH, Prakash CS (2001) Evaluation of genetic relationships among botanical varieties of cultivated peanut (Arachis hypogaea L.) using AFLP markers. Genet Resour Crop Evol 48: 347-352.

He GH, Meng R, Newman M, Gao G, Pittman RN, Prakash CS (2003) Microsatellites as DNA markers in cultivated peanut (Arachis hypogaea L.). BMC Plant Biol 3: 3.

Heffrer EL, Sorrells ME, Jannink JL (2009) Genomic selection for crop improvement. Crop Sci 49: 1-12.

Herselman L (2003) Genetic variation among Southern African cultivated peanut" Arachis hypogaea L.) genotypes as revealed by AFLP analysis. Euphytica 133:319-327.

Herselman LR, Thwaites FM, Kimmins B, Courtois PJA, Merwe VD, Seal SE (2004) Identification and mapping of AFLP markers linked to peanut (Arachis hypogaea L.) resistance to the aphid vector of groundnut rosette disease. Theor AppI Genet 109: 1426-1433.

Hilu KW, Stalker HT (1995) Genetic relationships between peanut and wild species of Arachis sect. Arachis (Fabaceae): evidence from RAPDs. Syst Evol 198: 167-178.

Holbrook CC, Dong W (2005) Development and evaluation of a mini core collection for the US peanut germplasm collection. Crop Sci 45: 1540-1544.

Holbrook CC, Ozias-Akins P, Chu Y, Guo B (2011) Impact of molecular genetic research on peanut cultivar development. Agronomy 1: 3-17.

Hong Y, Chen X, Liang X, Liu H, Zhou G, Li S, Wen S, Holbrook CC, Guo B (2010a) A SSRbased composite genetic linkage map for the cultivated peanut (Arachis hypogaea $\mathrm{L}$.) genome. BMC Plant Biol 10: 17.

Hong YB, Chen XP, Liu HY, Zhou GY, Li SX, Wen S), Liang XQ (2010b) Development and utilization of orthologous SSR markers in Arachis through soybean (Glycine max) EST. Acta Agron Sin 36: 410-421 (in Chinese with English abstract).

Hopkirs MS, Casa AM, Wang T, Mitchell SE, Dean RE, Kochert GD, Kresovich S (1999) Discovery and characterization of polymorphic simple sequence repeats (SSRs) in peanut. Crop Sci 39: 1243-1247.

Jannink JL, Lorenz AJ, Iwata H (2010) Genomic selection in plant breeding: from theory to practice. Brief Func Genom 9: 166-177.

Jesubatham AM, Burow MD (2006) PeanutMap: an online genome database for comparative molecular maps of peanut. BMC Bioinformatics 7: 375 .

Jiang HF, Ren XP, Zhang XJ, Huang JQ, Lei Y, Yan LY, Liao BS, Upadhyaya HD, Holbrook CC (2010) Comparison of genetic diversity based on SSR markers between peanut mini core collections from China and ICRISAT. Acta Agron Sin 36: 1084-1091. 
Khedikar YP, Gowda MVC, Sarvamangala C, Patgar KV, Upadhyaya HD, Varshney RK (2010) A QTL study on late leaf spot and rust revealed one major QTL for molecular breeding for rust resistance in groundnut (Arachis hypogaea L.). Theor Appl Genet 121: 971-984.

Khera P, Ufadhyaya HD, Pandey MK, Roorkiwal M, Sriswathi M, Janila P, Guo X, McKain MR, Nagy ED, Knapp SJ, Leebens-Mack J, Conner JA, Ozias-Akins P, Varshney RK (2013) $\mathrm{SNP}$-based genetic diversity in the reference set of peanut (Arachis spp.) by developing and applying cost-effective KASPar genotyping assays. The Plant Genome 6, doi: 10.3835/ plantgenome2013.

Kianian SF, Quiros CF (1992) Generation of a Brassica oleracea composite RFLP map: linkage arrangements among various populations and evolutionary implications. Theor Appl Genet 84: 544-554.

Kilian A (2008) DArT-based whole genome profiling and novel information technologies in support system of modern breeding of groundnut. In: Proc 3rd Int Conf for Peanut Genomics and Biotechnology on "Advances in Arachis through Genomics and Biotechnology (AAGB), 4-8 Nov 2008, Hyderabad, India.

Kochert G, Stalker HT, Gimenes M, Galgaro L, Lopes CR, Moore K (1996) RFLP and cytogenetic evidence on the origin and evolution of allotetraploid domesticated peanut, Arachis hypogaea (Leguminosae). Am J Bot 83: 1282-1291.

Koilkonda P, Sato S, Tabata S, Shirasawa K, Watanabe A, Wada T, Kishida Y, Tsuruoka H, Fujishiro T, Yamada M, Kohara M, Suzuki S, Hasegawa M, Kiyoshima H, Isobe S (2011) Large-scale development of expressed sequence tag-derived simple sequence repeat markers and diversity analysis in Arachis spp. Mol Breed DOI: 10.1007/s11032-011$9604-8$.

Krapovickas A, Gregory WC (1994) Taxonomia del género Arachis (Leguminosae). Bonplandia 8: 1-186.

Leal-Bertioli SCM, José AC, Alves-Freitas DM, Moretzsohn MC, Guimarães PM, Nielen S, Vidigal BS, Pereira RW, Pike J, Fávero AP, Parniske M, Varshney RK, Bertioli DJ (2009) Identification of candidate genome regions controlling disease resistance in Arachis. BMC Plant Biol 9: 112.

Leal-Bertioli SCM, Moretzsohn MC, Guimarães PM, Santos SP, Nielen S, Araujo ACG, Brasileiro ACM, Morgante CM, Bertioli DJ (2011) Broadening the genetic base of peanut: Introgression of wild Arachis resistance genes using the Tetraploid Route with the aid of molecular and cytogenetic markers. In: Proc 5th Int Conf for Peanut Genomics and Biotechnology on "Advances in Arachis through Genomics and Biotechnology (AAGB), 13-15th June 2011, Brasília, Brazil.

Liang X, Zhou G, Hong X, Chen X, Liu H, Li S (2009a) Overyiew of research progress on peanut (Arachis hypogaea L.) host resistance to aflatoxin contamination and genomics at the Guangdong Academy of Agricultural Sciences. Peanut Sci 36: 29-34.

Liang X, Chen X, Hong X, Liu H, Zhou G, Li S, Guo B (2009b) Utility of EST-derived SSR in cultivated peanut (Arachis hypogaen L.) and Arachis wild species. BMC Plant Biol 9: 35.

Luo M, Dang P, Guo B, He G, Holbrook CC, Bausher MG, Lee RD (2005) Generation of expressed sequence tags (ESTs) for gene discovery and marker development in cultivated peanut. Crop Sci 45: 346-353.

Mace ES, Varshney RK, Mahalakshmi V, Seetha K, Gafoor A, Leeladevi Y, Crouch JH (2007) In silico development of simple sequence repeat markers within the aeschynomenoid/ dalbergoid and genistoid clades of the leguminosae family and their transferability to Arachis hypogaea, groundnut. Plant Sci 174: 51-60.

Macedo SE, Moretzsohn MC, Leal-Bertioli SCM, Alves DMT, Gouvea EG, Azevedo VCR, Bertioli DJ (2012) Development and characterization of highly polymorphic long TC repeat microsatelite markers for genetic analysis of peanut. BMC Res Notes 5: 86 .

Mallikarjuna N, Senthilvel S, Hoisington D (2011) Development of new sources of tetraploid Arachis to broaden the genetic base of cultivated groundnut (Arachis hypogaea L.). Genet Resour Crop Evol 58: 889-907. 
Marcel TC, Varshney RK, Barbieri M, Jafary H, de Kock MJ, Graner A, Niks RE (2007) A highdensity consensus map of barley to compare the distribution of QTLs for partial resistance to Puccinia hordei and of defence gene homologues. Theor Appl Genet 114: 487-500.

Milla SR (2003) Relationships and utilization of Arachis germplasm in peanut improvement. PhD Thesis, North Carolina State Univ, USA, p 150.

Moretzsohn MC, Hopkins MS, Mitchell SE, Kresovich S, Valis JFM, Ferreira ME (2004) Genetic diversity of peanut (Arachis hypogaea L.) and its wild relatives based on the analysis of hyper variable regions of the genome. BMC Plant Biol 4: 11.

Moretzsohn MC, Leoi L, Proite K, Guimaras PM, LeaI-Bertioli SCM, Gimenes MA, Martins WS, Valls JFM, Grattapaglia D, Bertioli DJ (2005) A microsatellite-based, gene-rich linkage map for the AA genome of Arachis (Fabaceae). Theor Appl Genet 111: 1060-1071.

Moretzsohn MC, Barbosa AVG, Alves-Freitas DMT, Teixeira C, Leal-Bertioli SC (2009) A linkage map for the B-genome of Arachis (Fabaceae) and its synteny to the A-genome. BMC Plant Biol 9: 40.

Nagy E, Guo S, Khanal S, Taylor C, Ozias-Akins P, Stalker HT, Nielsen N (2010a) Developing a high density molecular map of the A-genome species A. duranensis. In: Proc American Peanut Research and Education Society (APRES), 12-15 July 2010, Florida, USA.

Nagy E, Chu X, Guo Y, Khanal S, Tang S, Li X, Dong W, Timper P, Taylor C, Ozias-Akins P, Holbrook C, Beilinson V, Nielsen N, Stalker T, Knapp S (2010b) Recombination is suppressed in an alien introgression in peanut harboring $R m a$, a dominant root-knot nematode resistance gene. Mol Breed 26: 357-370.

Naito Y, Suzuki S, Iwata X, Kuboyama T (2008) Genetic diversity and relationship analysis of peanut germplasm using SSR markers. Breed Sci 58: 293-300.

Nelson MN, Phan HTT, Ellwood SR, Paula MM, Hane J, Williams A, Lone CE, Nyarko JF, Scobie M, Cakir M, Jones MGK, Bellgard M, Wolko B, Barker SJ, Oliver RP, Cowling WA (2006) The first gene-based map of Lupinus angustifolius L.-location of domestication genes and conserved synteny with Medicago truncatula. Theor Appl Genet 113: 225-238.

Palmieri DA, Hoshino AA, Bravo JP, Lopes CR, Gimenes MA (2002) Isolation and characterization of microsatellite loci from the forage species Arachis pintoi (Genus Arachis). Mol Ecol Notes 2: 551-553.

Palmieri DA, Bechara MD, Curi RA, Gimenes MA, Lopes CR (2005) Novel polymorphic microsatellite markers in section Caulorrhizae (Arachis, Fabaceae). Mol Ecol Notes 5: $77-79$.

Pandey MK, Monyo E, Ozias-Akins P, Liang X, Guimarães P, Nigam SN, Upadhyaya HD, Janila P, Zhang X, Guo B, Cook DR, Bertioli DJ, Michelmore R, Varshney RK (2012a) Advances in Arachis genomics for peanut improvement. Biotechnol Adv 30: 639-651.

Pandey MK, Gautami B, Jayakumar T, Sriswathi M, Upadhyaya HD, Gowda MVC, Radhakrishnan T, Bertioli DJ, Knapp SJ, Cook DR, Varshney RK (2012b) Highly informative genic and genomic SSR markers to facilitate molecular breeding in cultivated groundnut (Arachis hypogaea). Plant Breed 131: 139-147.

Pandey MK, Feng S, Culbreath A, Varshney RK, Wang ML, Barkley NA, Holbrook CC, Guo B (2012c) Saturation of genetic maps for identification of QTLs controlling biotic resistance, morphological descriptors and oil quality in tetraploid peanut (Arachis hypogaea). In: Proc American Peanut Research and Education Society (APRES), 9-11 July 2012, Raleigh, USA, $\mathrm{p} 27$.

Proite K, Leal-Bertioli SC, Bertioli DJ, Moretzsohn MC, da Silva FR, Martins NF, Guimarães PM (2007) ESTs from a wild Arachis species for gene discovery and marker development. BMC Plant Biol 7: 7.

Qin H, Feng S, Chen C, Guo X, Krapp S, Culbreath A, He G, Wang ML, Zhang X, Holbrook CC, Ozias-Akins P, Guo B (2012) An integrated genetic linkage map of cultivated peanut (Arachis hypogaea L.) constructed from two RIL populations. Theor Appl Genet 124: 653-664.

Ravi K, Vadez V, Isobe S, Mir RR, Guo X, Nigam SN, Gowda MVC, Radhakrishnan T, Bertioli DJ, Knapp SJ, Varshney RK (2011) Identification of several small-effect main QTLs and 
larg number of epistatic QTLs for drought tolerance in groundnut (Arachis hypogaen L.). Theor Appl Genet 122: 1119-1132.

Ribaut JM, Hoisington D (1998) Marker-assisted selection: new tools and strategies. Trends Plant Sci 3: 236-239.

Ribaut1 JM, Ragot M (2007) Marker-assisted selection to improve drought adaptation in maize: the backcross approach, perspectives, limitations, and alternatives. J Exp Bot 58: 351-360.

Sarvamangala C, Gowda MVC, Varshney RK (2011) Identification of quantitative trait loci for protein content, oil content and oil quality for groundnut (Arachis hypogaea L.). Field Crops Res 122: 49-59.

Selvaraj MG, Narayana M, Schubert AM, Ayers JL, Baring MR, Burow MD (2009) Identification of QTLs for pod and kernel traits in cultivated peanut by bulked segregant analysis. Elec J Biotechnol 12, DOI:10.2225/vol12.

Sharopova N, McMullen MD, Schultz L, SchroederS, Sanchez-Villeda H, Gardiner J, Bergstrom D, Houchins K, Melia-Hancock S, Musket T, Duru N, Polacco M, Edwards K, Ruff T, Register JC, Brouwer C, Thompson R, Velasco R, Chin E, Lee M, Woodman-Clikeman W, Long MJ, Liscum E, Cone K, Davis G, Coe EH Jr (2002) Development and mapping of SSR markers for maize. Plant Mol Biol 48: 463-481.

Shirasawa K, Koilkonda P,Aoki K, Hirakawa H, Tabata S, Watanabe M, Hasegawa M, Kiyoshima H, Suzuki S, Kuwata C, Naito Y, Kuboyama T, Nakaya A, Sasamoto S, Watanabe A, Kato M, Kawashima K, Kishida Y, Kohara M, Kurabayashi A, Takahashi C, Tsuruoka H, Wada T, Isobe S (2012a) In silico polymorphism analysis for the development of simple sequence repeat and transposon markers and construction of linkage map in cultivated peanut. BMC Plant Biol 12: 80 .

Shirasawa K, Hirakawa $H$, Tabata S, Hasegawa M, Kiyoshima H, Suzuki S, Sasamoto S, Watanabe A, Fujishiro T, Isobe $S(2012 b)$ Characterization of active miniature invertedrepeat transposable elements in the peanut genome. Theor Appl Genet 124: 1429-1438.

Shirasawa K, Bertioli DJ, Varshney RK, Moretzsohn MC, Leal-Bertioli SCM, Thudi M, Pandey MK, Rami J-F, Foncéka D, Gowda MVC, Qin H, Guo B, Hong Y, Liang X, Hirakawa H, Tabata S, IsobeS (2013) Integrated consensus map of cultivated peanut and wild relatives reveals structures of the $A$ and $B$ genomes of Arachis and divergence of the legume genomes. DNA Res, pp 1-12, doi:10.1093/dnares/dss042.

Simpson CE (1991) Pathways of introgression of pest resistance into Arachis hypogaea L. Peanut Sci 18: 22-26.

Simpson CE (2001) Use of wild Arachis species/introgression of genes into A. hypogaea L. Peanut Sci 28: 114-116.

Simpson CE, Starr JL, Church GT, Burow MD, Paterson AH (2003) Registration of 'NemaTAM' peanut. Crop Sci 43: 1561.

Singh KP, Raina SN, Singh AK (1996) Variation in chromosomal DNA associated with the evolution of Arachis species. Genome 39: 890-897.

Somers DJ, Isaac P, Edwards K (2004) A high-density microsatellite consensus map for bread wheat (Triticum aestivum L.). Theor Appl Genet 109: 1105-1114.

Song GQ, Li MJ, Xiao H, Wang XJ, Tang RH, Xia H, Zhao CZ, Bi YP (2010) EST sequencing and SSR marker development from cultivated peanut (Arachis hypogaea L.). Elec) Biotechnol 13, DOI:10.2225/vol13.

Song QJ, Marek LF, Shoemaker RC, Lark KG, Concibido VC, Delannay X, Specht JE, Cregan PB (2004) A new integrated genetic linkage map of the soybean. Theor Appl Genet 109: 122-128.

Stalker HT, Beute MK, Shew BB, Isleib TG (2002) Registration of five leaf spot-resistant peanut germplasm lines. Crop Sci 42: 314-316.

Subramanian V, Gurtu S, Nageswara Rao RC, Nigam SN (2000) Identification of DNA polymorphism in cultivated groundnut using random amplified polymorphic DNA (RAPD) assay. Genome 43: 656-660. 
Sujay V, Gowda MVC, Pandey MK, Bhat RS, Khedikar YP, NadafHL, Gautami B, Sarvamangala C, Lingaraju S, Radhakrishan T, Knapp SJ, Varshney RK (2012) QTL analysis and construction of consensus genetic map for foliar diseases resistance based on two RIL populations in cultivated groundnut (Arachis hypogaea L.). Mol Breed 32: 773-788.

Tanksley SD, Nelson JC (1996) Advanced backcross QTL analysis: a method for the simultaneous discovery and transfer of valuable QTLs from unadapted germplasm into elite breeding lines. Theor Appl Genet 92: 191-203.

Upadhyaya HD, Ortiz R, Bramel PJ, Singh S (2003) Development of a groundnut core collection using taxonomical, geographical and morphological descriptors. Genet Resour Crop Evol 50: 139-148.

Varshney RK, Graner A, Sorrells ME (2005) Genomics-assisted breeding for crop improvement. Trends Plant Sci 10: 621-630.

Varshney RK, Hoisington DA, Tyagi AK (2006) Advances in cereal genomics and applications in crop breeding. Trends Biotechnol 24: 490-499.

Varshney RK, Marcel TC, Ramsay L, Russell J, Röder MS, Stein N, Waugh R, Langridge P, Niks RE, Graner A (2007) A high density barley microsatellite consensus map with 775 SSR loci. Theor Appl Genet 114: 1091-1103.

Varshney RK, Close TJ, Singh NK, Hoisington DA, Cook DR (2009a) Orphan legume crops enter the genomics era. Curr Opin Plant Biol 12: 202-210.

Varshney RK, Hoisington DA, Nayak SN, Graner A (2009b) Molecular plant breeding: Methodology and achievements. In: Somers D, Langridge P, Gustafson PJ (eds) Methods in Molecular Biology: Plant Genomics. Humana Press, Totowa, NJ, USA, pp 283-304.

Varshney RK, Bertioli DJ, Moretzsohn MC, Vadez V, Krishnamurthy L, Aruna R, Nigam SN, Moss BJ, Seetha K, Ravi K, He G, Knapp SJ, Hoisington DA (2009c) The first SSR-based genetic linkage map for cultivated groundnut (Arachis hypogaea L.). Theor Appl Genet 118: 729-739.

Varshney RK, Thudi M, May GD, Jackson SA (2010a) Legume genomics and breeding. Plant Breed Rev 33: 257-304.

Varshney RK, Glaszmann JC, Leung H, Ribaut JM (2010b) More genomic resources for lessstudied crops. Trends Biotechnol 28: 452-460.

Varshney RK, May GD (2012) Next-generation sequencing technologies: opportunities and obligations in plant genomics. Brief Funct Genom 11: 1-2.

Varshney RK, Mohan SM, Gaur PM, Gangarao NVPR, Pandey MK, Bohra A, Sawargaonkar S, Kimurto PK, Janila P, Saxena KB, Fikre A; Sharma M, Pratap A, Tripathi S, Datta S, Chaturvedi SK, Anuradha G, Babbar A, Chaudhary RG, Mhase MB, Bharadwaj CH, Mannur DM, Harer PN, Guo B, Liang X, Nadarajan N, Gowda CLL (2013a) Achievements and prospects of genomics-assisted breeding in three legume crops of the semi-arid tropics. Biotechnol Adv http://dx.doi.org/10.1016/j.biotechadv.2013.01.001.

Varshney RK, Pandey MK, Janila P, Nigam SN, Sudhini H, Gowda MVC, Sriswathi M, Radhakrishnan T, Manohar SS, Nagesh P (2013b) Marker-assisted introgression of a QTL region improved rust resistance in three varieties of peanut (Arachis hypogaea L.). Theor Appl Genet, under review.

Wang CT, Yang XD, Chen DX, Yu SL, Liu GZ, Tang $X Y$, Xu JZ (2007) Isolation of simple sequence repeats from groundnut. Elec J Biotechnol 10: 3 .

Wang H, Penmetsa RV, Yuan M, Gong L, Zhao Y, Guo B, Farmer AD, Rosen BD, Gao J, Isobe S, Bertioli DJ, Varshney RK, Cook DR, He G (2012) Development and characterization of BAC-end sequence derived SSRs, and their incorporation into a new higher density genetic map for cultivated peanut (Arachis hypogaea L.). BMC Plant Biol 12: 10.

Wang H, Pandey MK, Qiao L, Qin H, Culbreath AK, He G, Varshney RK, Guo B (2013) Genetic mapping and QTL analysis for disease resistance using $\mathrm{F}_{2}$ and $\mathrm{F}_{5}$ generation-based genetic maps derived from Tifrunner $\times$ GT-C20 in peanut (Arachis hypogaea L.). The Plant Genome 6, doi: 10.3835 / plantgenome2013.05.0018.

Xu Y, Crouch JH (2008) Marker-assisted selection in plant breeding: from publications to practice. Crop Sci 48: 391-407. 
Young ND, Weeden NF, Kochert G (1996) Genome mapping in legumes (Family Fabaceae). In: Paterson AH (ed) Genome Mapping in Plants. Landes Biomedical Press, Texas, USA, pp 211-277.

Yuan M, Gong L, Meng R, Li S, Dang P, Guo B, He G (2010) Development of trinucleotide $(\text { GGC) })_{n}$ SSR markers in peanut (Arachis hypogaea L.). Elec J Biotechnol DOI:10.2225/ vol13-issue6-fulltext-6.

Zhao Y, Prakash CS, He G (2012) Characterization and compilation of polymorphic simple sequence repeat (SSR) markers of peanut from public database. BMC Res Notes 5: 362. 